\title{
LA MIGRATION DE DÉVALAISON : PROBLÈMES ET DISPOSITIFS
}

\author{
F. TRAVADE ${ }^{\star}$ et M. LARINIER ${ }^{\star *}$
}

\footnotetext{
* EDF - Etudes et Recherches - 6, Quai Watier - 78401 CHATOU CEDEX

** CSP-CEMAGREF, GHAAPPE - Institut de Mécanique des Fluides - Avenue du Professeur Camille Soula - 31400 TOULOUSE
}

\section{ESPÈCES ET STADES CONCERNÉS PAR LA DÉVALAISON}

La dévalaison ou "avalaison", c'est-à-dire la migration qui s'effectue en descendant les cours d'eau vers la mer ou vers un lac concerne les juvéniles des espèces potamotoques (saumon, truite de mer, truite de lac, truite, alose), les adultes d'espèces potamotoques après la reproduction (salmonidés, alose finte) et les adultes d'espèces thalassotoques avant la reproduction (anguille).

\section{PROBLĖMES POSÉS DANS LES COURS D'EAUX AMÉNAGÉS}

Les divers problèmes posés aux migrateurs lors de la dévalaison ont plusieurs origines : modifications du milieu résultant de la création de retenues, transit dans les déversoirs et évacuateurs de crues, transit dans les turbines hydroélectriques, entraînement dans les prises d'eau industrielles ou agricoles.

En règle générale, l'ensemble de ces problèmes a été bien étudié sur les salmonidés ; par contre l'on dispose de relativement peu d'information sur les autres familles de migrateurs.

\subsection{Effets dûs à la présence de retenues}

La création d'une retenue sur un cours d'eau induit des modifications des vitesses d'écoulement, de la qualité de l'eau et des peuplements piscicoles qui peuvent entraîner une augmentation parfois importante des mortalités au cours de la migration de dévalaison : augmentation de la prédation par les oiseaux ou les poissons carnassiers (jusqu'à $85 \%$ de mortalité des smolts dans une retenue écossaise), mortalité directe dans les retenues eutrophisées, sensibilité accrue aux maladies et au parasitisme... L'importance de ces mortalités peut être très variable suivant les sites.

Les solutions relèvent de mesures de gestion (amélioration de la qualité de l'eau des retenues) ou de compensation (déversement de juvéniles pour compenser les mortalités).

\subsection{Passage par les déversoirs et évacuateurs de crues}

Le passage par les déversoirs et évacuateurs de crues (BELL et DELACY, 1972 ; RUGGLES, 1980 ; RUGGLES et MURRAY, 1983 ; BOYER-BERNARD, 1991) peut entraîner des mortalités directes (blessures, chocs...) ou indirectes (sensibilité accrue à la prédation des poissons choqués ou désorientés). Les études conduites sur plusieurs sites à l'étranger (USA, Canada...) ont montré que ces mortalités étaient extrêmement variables d'un site à l'autre : $0 \%$ à $4 \%$ pour les barrages de Bonneville et McNary (27 m de hauteur) sur la rivière Columbia, $17 \%$ à $64 \%$ pour les barrages de Baker river $(76 \mathrm{~m})$ et de Cleveland $(73 \mathrm{~m})$. 
Les causes de mortalités sont de plusieurs ordres : cisaillement hydraulique sur les déversoirs et dans les turbulences en pied de chute, variations brusques des vitesses et des pressions lors de l'impact sur le plan d'eau, chocs mécaniques sur les radiers ou les dissipateurs d'énergie.

Lors du franchissement d'un déversoir, le poisson, dans certains cas, se trouve en situation de chute libre. II atteint cependant, à partir d'une certaine hauteur de chute, une vitesse limite qui est fonction de sa taille : environ $12 \mathrm{~m} / \mathrm{s}$ (vitesse atteinte après 25-30 m de chute) pour des poissons de 10 à $13 \mathrm{~cm}, 15-16 \mathrm{~m} / \mathrm{s}$ (au bout de 30-40 mètres) pour des poissons de 15 à $18 \mathrm{~cm}$, plus de $58 \mathrm{~m} / \mathrm{s}$ (atteinte après plus de $200 \mathrm{~m}$ de chute) pour des poissons de $60 \mathrm{~cm}$.

Des expérimentations ont mis en évidence l'apparition de dommages significatifs (lésions au niveau des branchies, des yeux et des organes internes) dès que la vitesse d'impact du poisson sur le plan d'eau dépasse $15-16 \mathrm{~m} / \mathrm{s}$ et ce, quelle que soit sa taille (BELL et DELACY, 1972). Cette vitesse critique est atteinte après une chute variable suivant la taille du poisson : environ $30-40 \mathrm{~m}$ pour des poissons de $15-18 \mathrm{~cm}$ et $13 \mathrm{~m}$ seulement pour les poissons d'une taille supérieure à $60 \mathrm{~cm}$.

Les poissons de taille inférieure à $10-13 \mathrm{~cm}$, dont la vitesse limite demeure inférieure à la vitesse critique, ne subissent aucun dommage quelle que soit la hauteur de la chute. Les poissons de taille plus importante ne subissent aucune mortalité tant que la vitesse d'impact demeure inférieure à cette vitesse critique de $16 \mathrm{~m} / \mathrm{s}$, ce qui correspond à une chute variant d'une douzaine de mètres pour les gros individus (taille $>60 \mathrm{~cm}$ ) à une trentaine de mètres pour les poissons de $18 \mathrm{~cm}$, pour qui la vitesse terminale est très proche de la vitesse critique.

Lorsqu'un poisson, entraîné par un déversoir, demeure confiné à l'intérieur de la lame d'eau, sa survie serait identique (BELL et DELACY, 1972) à celle résultant d'une chute libre induisant la même vitesse d'impact au niveau du plan d'eau. Une lame d'eau atteint la vitesse critique à partir de laquelle le poisson subit des dommages par cisaillement hydraulique au bout de $13 \mathrm{~m}$ de chute. Au-dessus de cette limite, les mortalités deviennent significatives et augmentent rapidement avec la chute ( $100 \%$ de mortalité pour 50-60 m de chute).

En conclusion, pour les poissons de petite taille (longueur inférieure à 15-18 cm), il est toujours moins dommageable de tomber en chute libre dans la mesure où leur vitesse terminale est inférieure à la vitesse critique de $16 \mathrm{~m} / \mathrm{s}$; pour les poissons de plus grande taille, il est équivalent de tomber en chute libre ou de demeurer confiné dans la lame d'eau.

Les déversoirs en "saut de ski", où la vitesse d'impact sur le plan d'eau peut être réduite et où le poisson a la possibilité de tomber en chute libre en dehors de la veine d'eau, sont préférables aux autres types d'évacuateurs, et ceci tout particulièrement pour les poissons de petite taille.

Dans tous les cas, les chances de survie sont d'autant plus grandes que la turbulence au pied de la chute est faible et que les chocs mécaniques sont réduits (volume d'eau important, absence de dissipateurs d'énergie ou plus généralement de structures agressives).

A ces risques de mortalité directe, vient s'ajouter un risque de mortalité indirecte. Les traumatismes et/ou la désorientation des poissons après la chute les rendent plus sensibles à la prédation par des oiseaux ou par des poissons carnassiers : jusqu'à $30 \%$ de mortalité ont pu être observés sur certains sites (RUGGLES et MURRAY, 1983).

\subsection{Passage dans les turbines hydrauliques}

Le passage à travers les turbines hydrauliques soumet le poisson à diverses contraintes susceptibles d'entraîner des mortalités importantes : risques de chocs contre les parties fixes ou mobiles de la turbine (au niveau des directrices, des aubes ou des pales de la roue), accélération et décélération brutales (passage de $3-5 \mathrm{~m} / \mathrm{s}$ en entrée de roue à $10-30 \mathrm{~m} / \mathrm{s}$ dans la roue), variations très brutales de pression.

De nombreuses expérimentations ayant fait l'objet de plusieurs synthèses (BELL, 1981 ; MONTEN, 1985 ; MONTREAL ENGINEERING COMPANY, 1981 ; EPRI, 1987 ; 
LARINIER et DARTIGUELONGUE, 1989) ont été menées dans divers pays (USA, Canada, Suède, Ecosse, Allemagne, France), principalement sur les juvéniles de salmonidés, et plus rarement sur les clupéidés et les anguilles, pour déterminer les mortalités résultant du transit dans les principaux types de turbines.

Les mortalités sont totales dans les turbines du type Pelton mais fort heureusement ces turbines, réservées aux très hautes chutes, ne sont pas implantées sur les cours d'eau à migrateurs.

Les mortalités des juvéniles de salmonidés dans les turbines Francis et Kaplan sont très variables en fonction des caractéristiques de la roue (diamètre, vitesse de rotation...), de leur régime de fonctionnement, de la hauteur de chute ainsi que de l'espèce et de la taille du poisson concerné. Elles varient de moins de $5 \%$ à plus de $90 \%$ dans les turbines Francis. Elles sont en moyenne plus faibles dans les turbines Kaplan, de $5 \%$ à $20 \%$ environ. Les mortalités peuvent s'avérer plus importantes pour certaines espèces, en particulier les espèces physoclistes $\left(^{*}\right)$, plus sensibles aux variations de pression et l'anguille, à cause de sa taille. Les juvéniles d'alose apparaissaient jusqu'à présent beaucoup plus sensibles que les salmonidés (mortalités de $65 \%$ à $85 \%$ dans les turbines où la mortalité des juvéniles de salmonidés est de l'ordre de $10 \%$ à $15 \%$ ) (TAYLOR et KYNARD, 1985). Des expérimentations récentes faisant appel à de nouvelles techniques (RUGGLES, 1992) laissent à penser que ces mortalités seraient en réalité du même ordre de grandeur que celles observées sur des salmonidés. Elles auraient été surestimées du fait des protocoles d'étude et des dispositifs de récupération utilisés jusqu'alors.

Diverses équations prédictives de la mortalité ont été proposées, avec plus ou moins de succès. Une étude récente réalisée en France (LARINIER et DARTIGUELONGUE, 1989) a permis d'obtenir des formules prédictives de mortalités sur les juvéniles de salmonidés et les anguilles dans les turbines Francis et Kaplan à partir des principales caractéristiques de la turbine et de la taille des poissons.

Dans le cas des turbines Francis, l'équation de régression expliquant le mieux la mortalité pour les juvéniles de salmonidés est la suivante :

$$
P=\left\{\operatorname{SIN}\left(-4.21+1.25 \mathrm{~V}^{0.821}+2.28 \mathrm{~N}^{0.19}(\text { TLesp })^{0.84} \mathrm{~W}^{0.71}\right)\right\}^{2} \quad(R=0.87)
$$

où $P$ est la part de mortalité (comprise entre 0 et 1$), V 1(\mathrm{~m} / \mathrm{s})$ et $W 1(\mathrm{~m} / \mathrm{s})$ les vitesses absolue et relative à l'entrée de la roue, $\mathrm{N}(\mathrm{trs} / \mathrm{mn})$ la vitesse de rotation de la roue, TL $(\mathrm{m})$ la longueur du poisson et esp $(\mathrm{m})$ l'espacement inter-aubes calculé à mi-aube en entrée de roue.

Pour les turbines Kaplan, les facteurs influant sur la mortalité sont moins évidents. Seuls interviennent de manière significative la longueur d'un poisson TL $(m)$ et l'espacement inter-pales calculé à mi-pale esp $(\mathrm{m})$ :

Pour les juvéniles de salmonidés:

$$
P=\{\operatorname{SIN}(13.4+42.8(T L / e s p))\}^{2}(R=0.59)
$$

Pour les anguilles:

$$
P=\{\operatorname{SIN}(28.6+48.7(T L / e s p))\}^{2}(R=0.85)
$$

\subsection{Entraînement dans les prises d'eau industrielles ou agricoles}

Du fait de leur comportement migratoire, les incitant à suivre le courant, les migrateurs en avalaison, sont susceptibles de se laisser entraîner dans tous les types de prises d'eau : centrales thermiques, usines, canaux d'irrigation... Les risques d'entraînement sont éminemment fonction des débits relatifs des pompages et des cours d'eau. Les dommages sont spécifiques à chacune des installations et doivent être examinés cas par cas.

(") Chez les poissons physostomes (salmonidés, clupéidés, cyprinidés), la régulation de la pression de la vessie natatoire peut se faire relativement rapidement par la bouche via le canal pneumatique. Chez les poissons physoclistes (perche, sandre), la régulation de la pression se fait beaucoup plus lentement par échange gazeux avec les vaisseaux sanguins de la paroi de la vessie natatoire. Le risque de rupture de la vessie natatoire suite à un abaissement brutal de pression est donc beaucoup plus important chez les espèces physoclistes que chez les espèces physostomes. 


\section{AMÉNAGEMENTS POUR LA DÉVALAISON}

\subsection{Possibilités de passage dans les turbines et/ou les déversoirs}

Au niveau d'une installation hydroélectrique, si les mortalités potentielles lors du transit par les déversoirs ou les turbines sont faibles, il peut s'avérer inutile de prévoir des dispositifs spéciaux pour la dévalaison. Ce choix a été fait sur plusieurs centrales en Ecosse et en Irlande, où le blocage prolongé des juvéniles au niveau des grilles des prises d'eau, dans l'attente de trouver l'entrée des exutoires leur permettant de passer à l'aval, s'est traduit par des mortalités par prédation (brochets, truites) bien supérieures à celles subies lors du transit par les turbines. Des résultats récents (RUGGLES, 1992) indiquent par ailleurs que les mortalités dans certains exutoires de dévalaison peuvent être du même ordre de grandeur, voire supérieures à celles résultant du transit dans les turbines.

Par ailleurs, sur les ouvrages d'une certaine taille, non équipés lors de leur construction de dispositifs de dévalaison, il est souvent très difficile, voire techniquement impossible, de détourner les poissons des déversoirs de crue ou des turbines. Lorsqu'il existe plusieurs déversoirs et/ou turbines de caractéristiques différentes, on favorisera dans la mesure du possible en période de dévalaison l'utilisation de celui/celle ou ceux présentant le moins de risques potentiels.

\subsection{Barrières physiques}

Une première solution pour empêcher le transit des poissons dans les turbines consiste à les arrêter au droit des prises d'eau, canaux d'amenée ou déversoirs par des grilles de porosité inférieure à leur taille.

L'installation de ces grilles au droit des prises d'eau classiques ou des canaux de dérivation requiert deux impératifs :

- présence d'exutoires à proximité,

- vitesses d'écoulement devant ces grilles suffisamment faibles pour permettre aux poissons de nager pendant le temps nécessaire à la découverte de ces exutoires (faute de quoi les mortalités par placage contre les grilles peuvent devenir supérieures à celles subies lors du transit dans les turbines).

En règle générale, les grilles utilisées en Amérique du Nord et en Ecosse sont à mailles carrées ou rectangulaires variant d'environ $5 \mathrm{~mm}$ à $25 \mathrm{~mm}$ suivant la taille des poissons à exclure, la vitesse d'écoulement au droit du plan de grille devant rester inférieure à $30 \mathrm{~cm} / \mathrm{s}$ pour les smolts et à $15 \mathrm{~cm} / \mathrm{s}$ pour les alevins (CLAY, 1961 ; AITKEN et al., 1966).

Divers types de grilles ont été utilisées:

- panneaux de grilles fines installés temporairement sur les grilles de prises d'eau (AITKEN et al., 1966). L'installation de ces grilles impose de très lourdes contraintes, tant de dimensionnement des prises d'eau (de façon à respecter les critères sur les vitesses) que d'entretien (nécessité de démontage des grilles par panneaux pour en effectuer le nettoyage). Ces grilles fines sont, la plupart du temps, impossibles à installer sur les prises d'eau existantes sur lesquelles les vitesses d'approche sont trop importantes,

- grilles rotatives auto-nettoyantes (utilisées dans les canaux d'irrigation aux USA) (NIETZEL et al., 1990, RAINEY, 1990). Ces grilles constituent une solution très efficace pour le détournement des poissons dans des canaux de faible profondeur $(\leq 2 \mathrm{~m})$. Leur coût reste cependant très élevé,

- grilles déflectrices installées à l'intérieur même des prises d'eau des turbines (WILLIAMS, 1990) destinées à détourner les poissons vers les puits à batardeaux à partir desquels ils peuvent accéder à un dispositif de dévalaison (rivière Columbia et affluents aux USA). Ces grilles restent réservées aux très grosses installations. Leur prix est élevé : plusieurs millions de francs par turbine,

- grilles "écrémeuses" ou grilles "Eicher" (EICHER, 1985) installées dans les galeries d'amenée d'eau vers les turbines dont le principe est de déflecter les poissons vers un by-pass à l'aide d'un écran incliné (Fig. 1). Cet écran est constitué d'une grille "Johnson" 
à barreaux de section triangulaire de $2 \mathrm{~mm}$ espacés de $2 \mathrm{~mm}$. La vitesse débitante dans la conduite est d'environ $1.5 \mathrm{~m} / \mathrm{s}$. Les vitesses normales au plan de grille et au droit du bypass sont respectivement de $0.45 \mathrm{~m} / \mathrm{s}$ et $1.5 \mathrm{~m} / \mathrm{s}$. L'avantage principal de ce type de grille est de pouvoir fonctionner à des vitesses élevées $(1.5 \mathrm{~m} / \mathrm{s}$ à $2.4 \mathrm{~m} / \mathrm{s})$. Elle s'est révélée par ailleurs pratiquement autonettoyante.

Les grilles "Eicher", compte tenu de leur efficacité sur des installations récentes et de leur possibilité de fonctionnement à vitesses élevées, semblent être les barrières physiques les plus prometteuses dans l'avenir immédiat (RUGGLES, 1992).
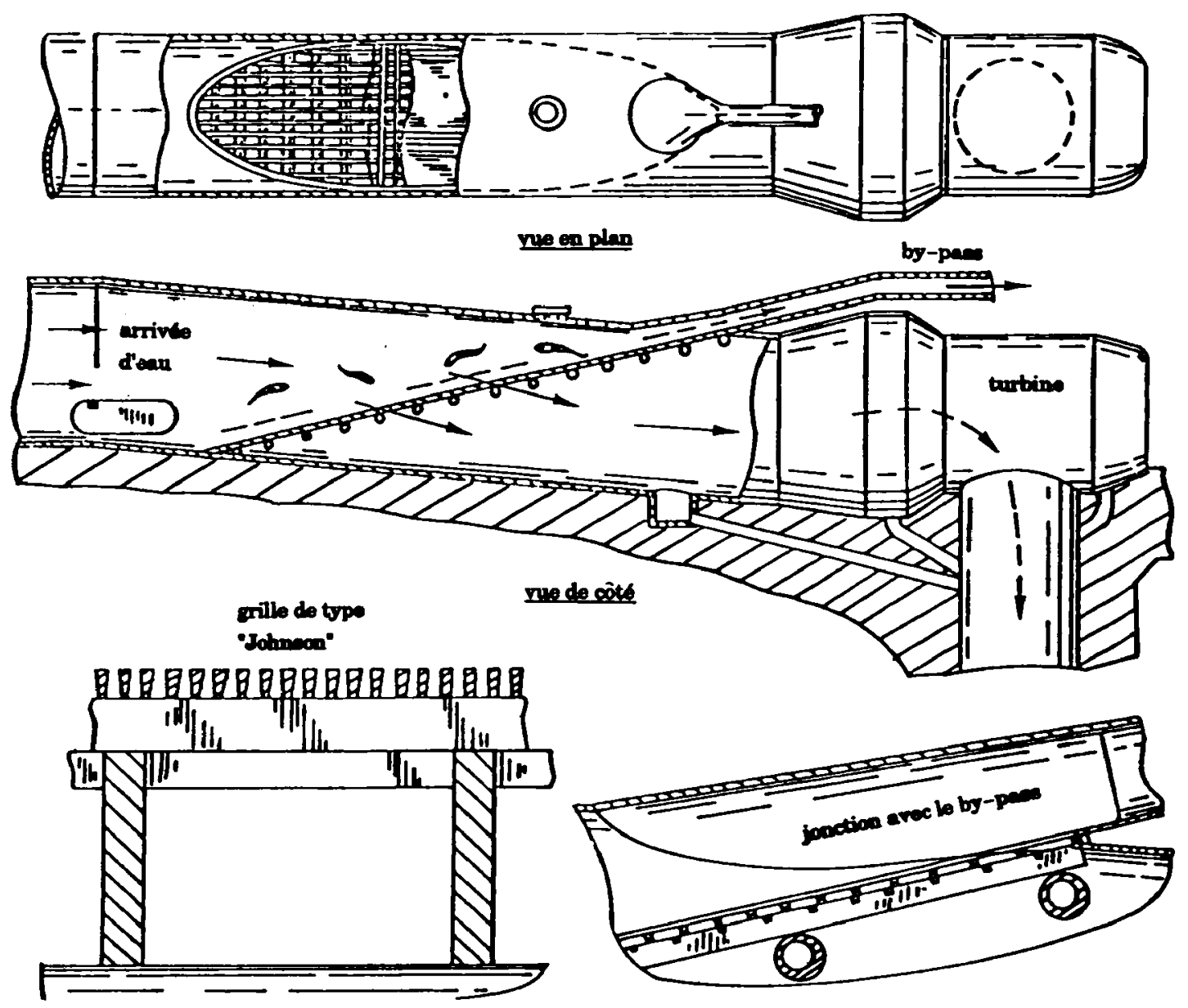

Figure 1 : Schéma de principe de la grille déflectrice de type "Eicher" installée à l'intérieur de la conduite d'amenée de la centrale de Sullivan (rivière Wilamette, USA). D'après EICHER, 1985.

Figure 1 : Schematic view of Eicher screen used to bypass fish at Sullivan hydroelectric power plant (river Wilamette, USA). From EICHER, 1985.

\subsection{Barrières comportementales}

Il s'agit de dispositifs induisant le déplacement des poissons dans une direction donnée grâce à divers stimuli agissant sur leur comportement (attraction, répulsion, guidage). Ces barrières sont "attrayantes" pour les concepteurs et exploitants car, au contraire des précédentes, elles ne présentent que de faibles contraintes de protection contre le colmatage et de nettoyage.

Les stimuli visuels, auditifs, hydrodynamiques, électriques ont donné lieu à un grand nombre de barrières expérimentales : écran à bulles, écran sonore, écran à chaînes fixes et mobiles, écran lumineux attractif ou répulsif, écran électrique, écran hydrodynamique ("louvers" ou écran à persiennes). 
Des résultats ponctuels ont été obtenus sur un certain nombre d'écrans (écran visuel à chaînes, écran lumineux, écran sonore...) mais ils n'ont pas donné, en général, d'applications grandeur réelle en raison de leur spécificité (efficacité fonction de l'espèce et de la taille), de leur faible fiabilité et de leur sensibilité aux conditions de milieu (turbidité de l'eau). Des tests sont encore en cours sur l'effet répulsif des sons ("poppers") mais, dans l'ensemble, les résultats ne sont pas concluants (EPRI, 1986 ; BOYER-BERNARD, 1991).

Les effets répulsifs (flashes stroboscopiques) ou attractifs (lampes à vapeur de mercure) de la lumière ne sont pas toujours très évidents, mais les expérimentations doivent être pousuivies car la lumière semble être un paramètre susceptible de renforcer les effets d'autres dispositifs.

Des résultats encourageants ont été obtenus récemment sur l'efficacité d'écrans lumineux répulsifs vis-à-vis de l'anguille adulte en avalaison (HADDERINGH et al, à paraître). Ces écrans, constitués d'ampoules immergées, utilisent le comportement lucifuge de l'anguille pour les détourner vers les zones d'ombre.

Seul l'écran hydrodynamique (Fig. 2) a été utilisé avec succès sur plusieurs installations, notamment aux USA dans les canaux d'irrigation (avec des débits allant jusqu'à $140 \mathrm{~m}^{3} / \mathrm{s}$ ) et à titre expérimental au niveau de prises d'eau de petites centrales hydroélectriques. Pour rester efficace, cet écran requiert cependant le respect d'un certain nombre de critères très précis:

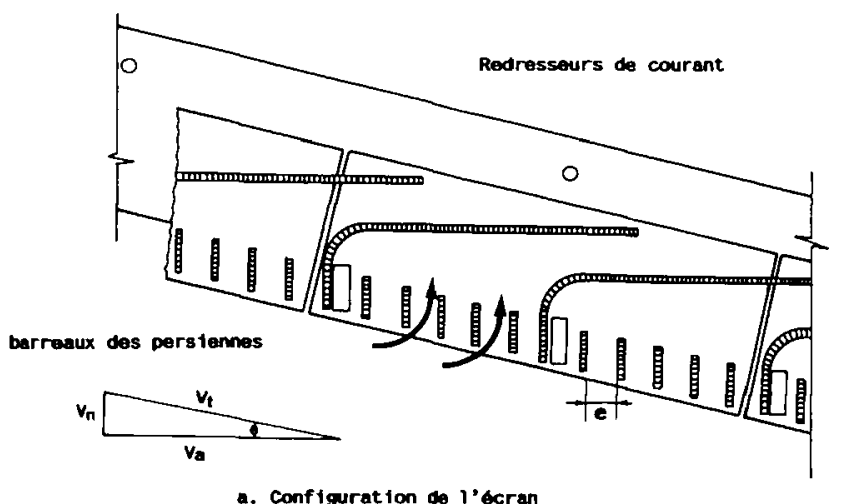

a. Configuration de l'ecran

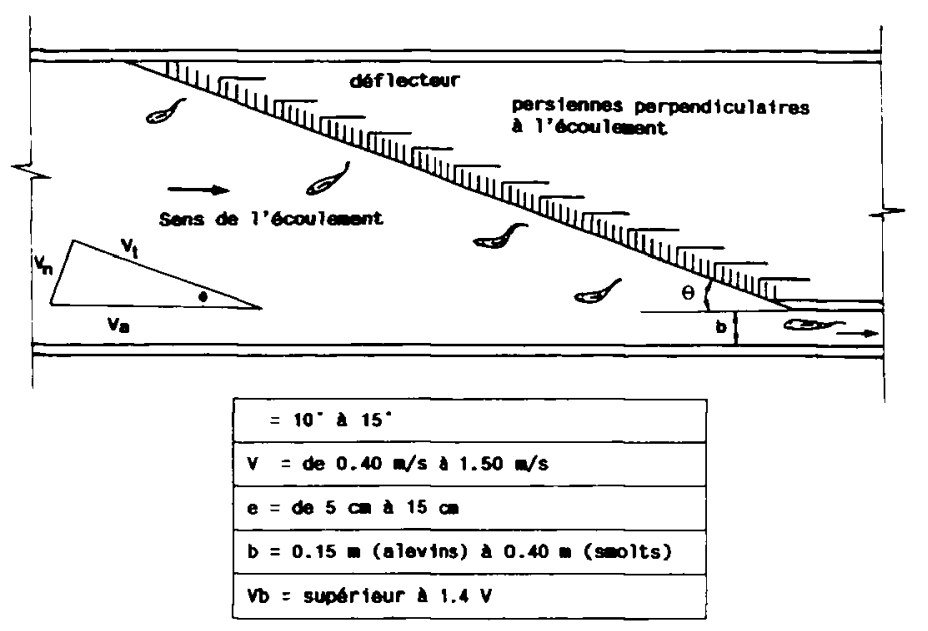

b. Principaux paradtres de dimansionnement

Figure 2 : Principaux critères de conception d'un écran hydrodynamique à persiennes (“louver”). D’après RUGGLES et RYAN, 1964 ; BATES, 1960.

Figure 2 : Characteristics of a louver screen. From RUGGLES and RYAN, 1964 ; BATES, 1960. 
- l'angle de l'écran par rapport à l'écoulement doit être compris entre $10^{\circ}$ et $15^{\circ}$, poisson,

- l'écartement des lames varie de moins de $5 \mathrm{~cm}$ à $15 \mathrm{~cm}$ suivant la taille du

- les vitesses d'écoulement à l'approche de l'écran doivent demeurer uniformes et constantes et être comprises entre $0.4 \mathrm{~m} / \mathrm{s}$ pour les alevins et $1.5 \mathrm{~m} / \mathrm{s}$ pour les smolts,

- la vitesse dans le by-pass doit être supérieure ou égale à 1.4 fois la vitesse d'écoulement à l'approche de l'écran.

Ce dispositif est par ailleurs très sensible au colmatage et nécessite des dispositifs de protection et de nettoyage. Aux USA, il est actuellement remplacé progressivement par les grilles rotatives inclinées (NIETZEL et al., 1990).

Des essais récents (RUGGLES, 1992) ont été conduits pour adapter ces écrans aux canaux d'amenée de centrales hydroélectriques à profondeur importante. Au barrage de Holyoke sur la rivière Connecticut (USA), un écran à persiennes flottant d'une longueur de $157 \mathrm{~m}$ a permis de déflecter près de $90 \%$ des juvéniles de salmonidés. L'utilisation de ces écrans pourrait donc présenter de nouvelles perspectives intéressantes.

\subsection{Exutoires de dévalaison (by-pass)}

Lorsque l'on veut éviter l'entraînement des poissons dans une prise d'eau, quel que soit le dispositif utilisé, il est nécessaire de disposer d'un ou plusieurs exutoires permettant aux poissons de contourner l'obstacle et de regagner sans dommage leur milieu d'origine (le canal de fuite ou l'aval du barrage dans le cas d'une installation hydroélectrique). Ces exutoires peuvent être associés à des barrières physiques ou comportementales, ou plus simplement utilisés seuls, à condition que leur implantation et conception soient telles que le poisson y soit attiré naturellement.

Il paraît peu réaliste d'envisager en France l'installation systématique de grilles fines telles que celles utilisées en Ecosse ou aux USA qui obligeraient à redimensionner la plupart des prises d'eau. C'est pourquoi on s'est orienté vers l'utilisation d'exutoires de surface, en mettant à profit la répulsion naturelle qu'éprouvent les poissons à franchir les grilles conventionnelles de protection des turbines.

Des expérimentations ont été entreprises dans le but de quantifier l'efficacité de tels exutoires et d'en optimiser l'implantation et le dimensionnement ainsi qu'à en augmenter l'attractivité en utilisant la lumière, dans la mesure où une grande partie de la migration se déroule de nuit (BOMASSI et TRAVADE, 1985 ; LARINIER et BOYER-BERNARD, 1991a, 1991b).

Les principales caractéristiques à donner pour un exutoire, telles qu'elles peuvent ressortir de ces premières expérimentations sont les suivantes (Fig. 3) :

- l'écoulement doit se faire en surface par des pertuis d'une largeur minimale de $0.5 \mathrm{~m}$ à $1 \mathrm{~m}$ (suivant la largeur de la prise d'eau)

- une lame d'eau minimale d'une quarantaine de centimètres y est nécessaire, ce qui correspond à un débit minimal de l'ordre de $0.5 \mathrm{~m}^{3} / \mathrm{s}$ par mètre de largeur,

- l'accélération dans l'exutoire doit être progressive, l'écoulement devant présenter un minimum de décollements et de zones de turbulences (installation éventuelle d'entonnements),

- le débit transitant par les exutoires doit être à l'échelle du débit turbiné. Un minimum de $2 \%$ à $5 \%$ est à prévoir,

- ces exutoires doivent être implantés le plus près possible du plan des grilles (latéralement ou au-dessus du plan de grilles) ou plus généralement de la zone de rassemblement des poissons,

Le transit vers l'aval se fait au moyen de buses ou canalets dans lesquels on doit éviter toute source de chocs, une rugosité excessive, des coudes à angle trop vifs, etc... La vitesse ne doit pas y excéder une douzaine de $\mathrm{m} / \mathrm{s}$ et il est préférable que cet ouvrage débouche à l'horizontale au-dessus du niveau d'eau aval (chute maximale de 1 à $3 \mathrm{~m}$ ). 


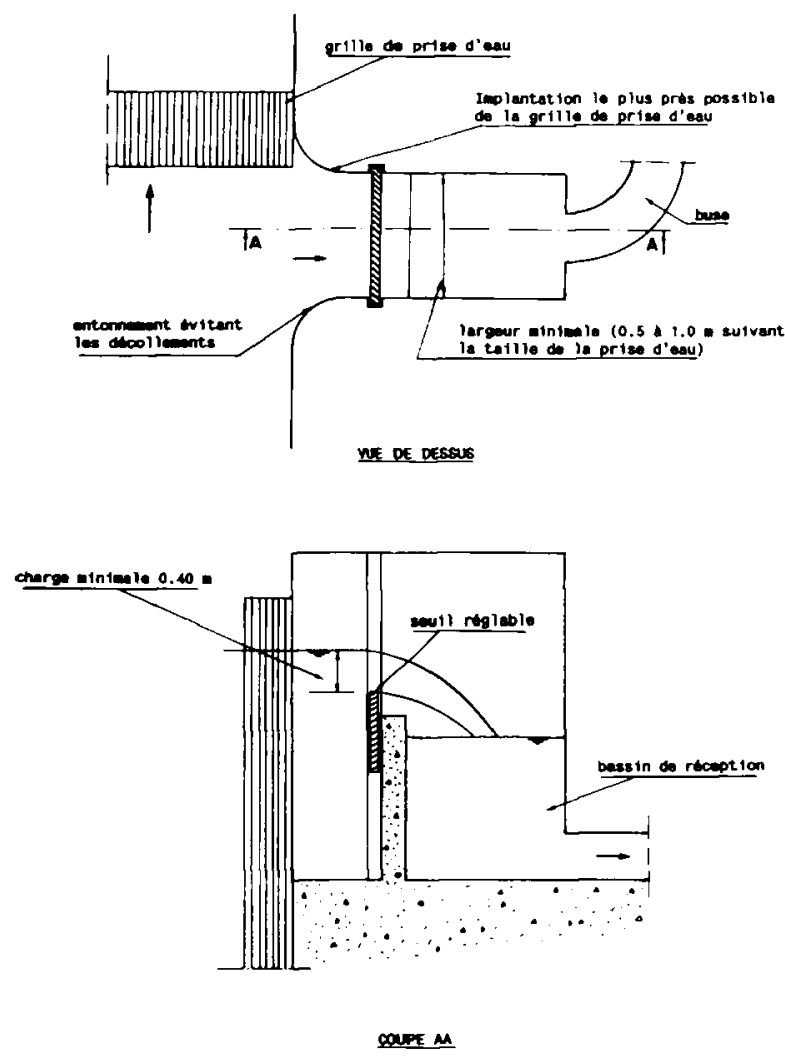

Figure 3 : Principales caractéristiques d'un exutoire de dévalaison de surface situé au droit des prises d'eau d'usines hydroélectriques.

Figure 3 : Characteristics of surface downstream bypasses at hydroelectric power plant intakes.

Le colmatage par les corps dérivants est le principal problème rencontré lors du fonctionnement de ces exutoires dans la mesure où les zones de rassemblement des poissons - et par conséquent la position des exutoires - correspondent aux zones d'accumulation des débris. Pour s'en affranchir, on peut soit dimensionner les buses et canalets de façon à permettre le passage à l'aval des corps dérivants, soit installer à l'amont immédiat de l'exutoire des grilles à barreaux à fort écartement (minimum $20 \mathrm{~cm}$ ) de façon à ne pas perturber le comportement des poissons.

Lorsque cela est possible, on aura intérêt à installer ce système de protection à l'aval d'un bassin tampon intercalé entre l'exutoire et la buse (ou le canalet) de restitution (Fig. 3).

Dès que la largeur de la prise d'eau dépasse une dizaine de mètres, il devient préférable d'installer plusieurs exutoires.

Le principe d'implantation de ces exutoires au niveau des prises d'eau a été schématisé sur la figure 4. Outre la configuration générale de la prise d'eau, il est nécessaire de tenir compte de l'hydrodynamique du site (nature de l'écoulement, courants transversaux au droit des grilles susceptibles de guider les poissons vers une zone particulière).

L'augmentation de l'attractivité de ces exutoires par la lumière, compte tenu du fait que la majeure partie de la dévalaison se déroule durant la nuit, offre d'intéressantes perspectives comme en témoignent les premiers résultats obtenus (LARINIER et BOYERBERNARD, 1991a et 1991b). Il apparaît cependant que l'efficacité est fortement dépendante des conditions d'éclairement (localisation, puissance, rythme d'allumage et d'extinction...). De plus amples expérimentations s'avèrent néanmoins nécessaires pour les définir précisément. 

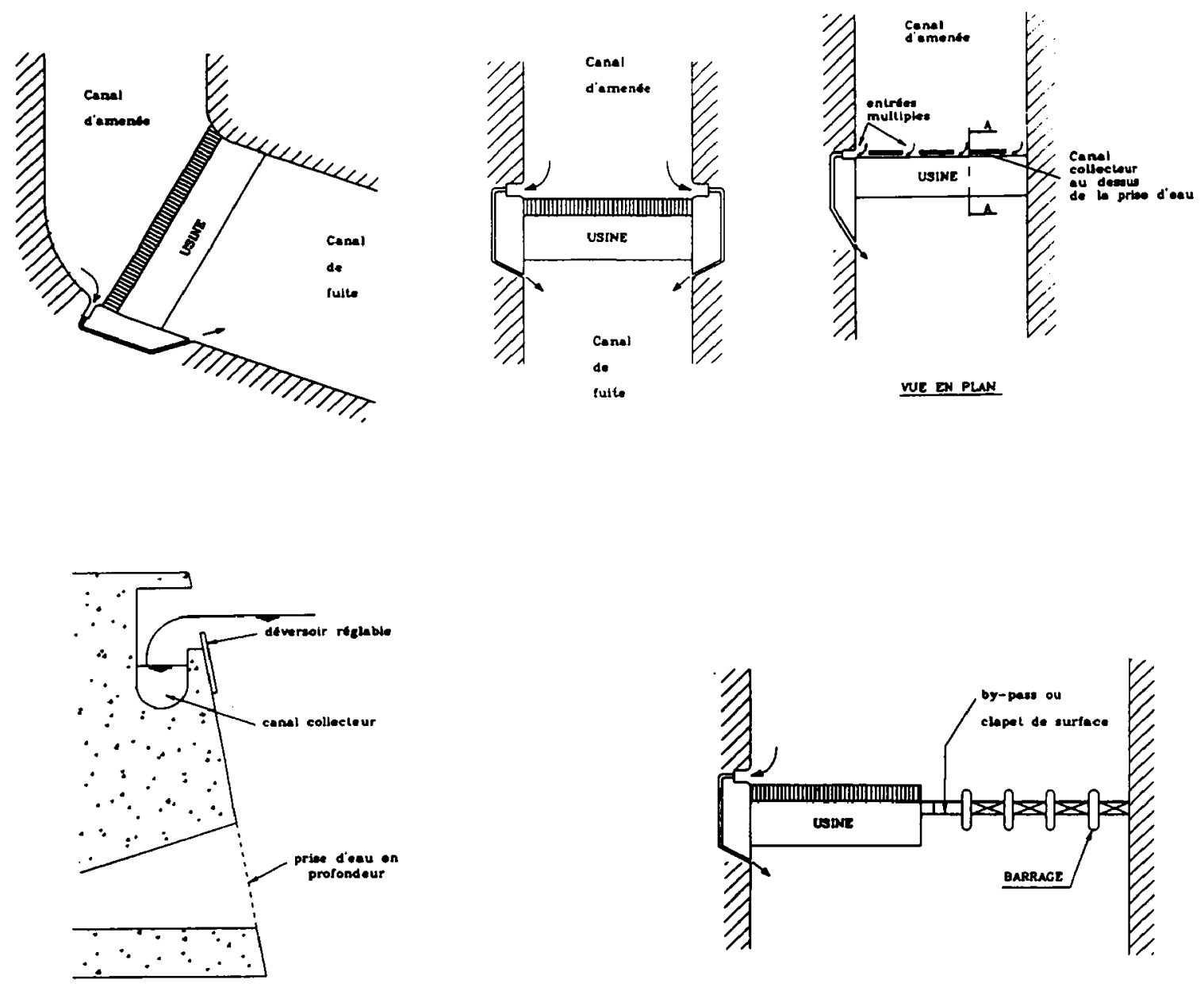

COUPE A - A
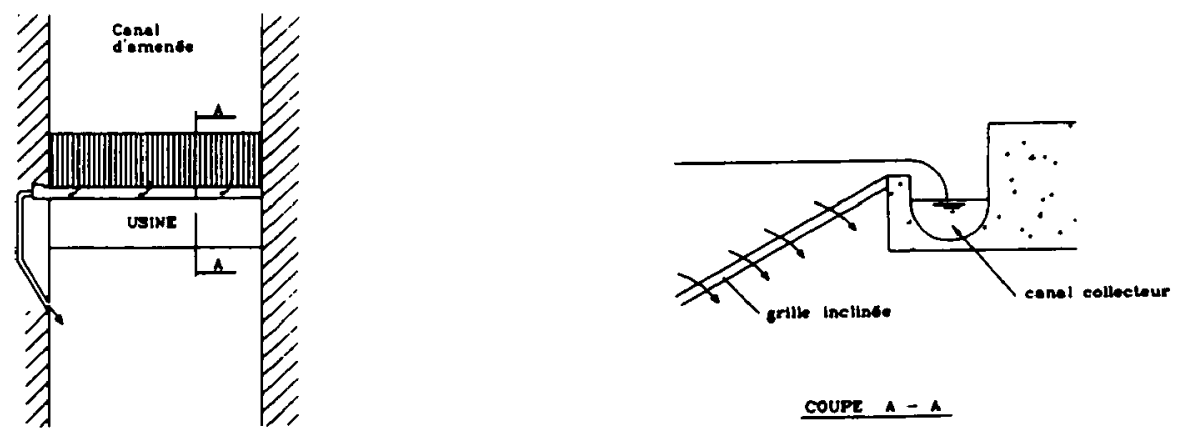

VUE EN PLN

Figure 4 : Situation des exutoires de dévalaison suivant la configuration de l'aménagement hydroélectrique.

Figure 4 : Location of downstream bypasses at hydroelectric power plant intakes. 
Les premiers résultats obtenus lors de contrôles d'exutoires réalisés récemment sur la côte Est des USA indiquent des efficacités de l'ordre de $15 \%$ (SAUNDERS, 1992). En France, les efficacités obtenues sur deux sites vont de $85 \%$ dans le cas d'un exutoire dont l'implantation était très favorable (usine d'Halsou, LARINIER et BOYER-BERNARD, 1991a) à environ $20 \%$ (usine de Soeix) pour un exutoire situé à $6 \mathrm{~m}$ en amont des grilles de prise d'eau.

L'efficacité de ces dispositifs se révèle très sensible à leur implantation et aux conditions hydrodynamiques avoisinantes. II semble urgent de mettre en oeuvre des programmes expérimentaux beaucoup plus conséquents que ceux existants à l'heure actuelle pour affiner les critères de conception et préciser les limites de ces dispositifs.

\section{BIBLIOGRAPHIE}

AITKEN P.L., DICKERSON L.H., MENZIES W.J.M., 1966. Fish passes and screens at water power works. Proc. Inst. Civ. Eng., $35: 29-57$.

BELL M.C., 1981. Updated compendium of the success of passages of small fish through turbines. Fish. Eng. Res. Prog., U.S. Army Corps of Eng., North Pacific Div., Portland, Oregon, $294 \mathrm{p}$.

BELL M.C., DELACY A.C., 1972. A compendium on the survival of fish passing through spillways and conduits. Fish. Eng. Res. Prog., U.S. Army Corps of Eng., North Pacific Div., Portland, Oregon, $121 \mathrm{p}$.

BOMASSI P., TRAVADE F., 1985. Projet de réimplantation du saumon dans la partie supérieure de l'Allier : expériences sur les possibilités de dévalaison des saumoneaux au barrage hydroélectrique de Poutès en 1983 et 1984. Colloque pour la restauration des rivières à saumons, $11 \mathrm{p}$.

BOYER-BERNARD S., 1991. Contribution à la définition de dispositifs d'évitement des centrales hydroélectriques pour les juvéniles de poissons migrateurs. Thèse de doctorat, INP Toulouse, $382 \mathrm{p}$.

CLAY C.H., 1961. Design of fishway and other fish facilities. Dept. of Fisheries, Ottawa, Canada, $301 \mathrm{p}$.

EICHER G.J., 1985. Fish passage : protection of downstream migrants. Hydro Rev., 5 p.

EPRI, 1986. Assessment of downstream migrant fish protection technology of hydroelectric application. Stone and Webster Eng. Corp., Boston, Massachussetts, 420 p.

EPRI, 1987. Turbine-related fish mortality : review and evaluation of studies. Res. Project 2694-4, Final Rep., 102 p.

HADDERINGH R.H., VAN DER STOEP J.W., HAGRAKEN J.M.P.M., (à paraître). Deflecting eels from water inlets of power stations with light. Irish Fish. Invest.

LARINIER M., BOYER-BERNARD S., 1991a. Dévalaison des smolts et efficacité d'un exutoire de dévalaison à l'usine hydroélectrique d'Halsou sur la Nive. Bull. Fr. Pisc., $321: 30-51$.

LARINIER M., BOYER-BERNARD S., 1991b. La dévalaison des smolts de saumon atlantique au barrage de Poutès sur l'Allier: utilisation de lampes à vapeur de mercure en vue d'optimiser l'efficacité de l'exutoire de dévalaison. Bull. Fr. Pisc., 323 : 129-148.

LARINIER M., DARTIGUELONGUE J., 1989. La circulation des poissons migrateurs : le transit à travers les turbines des installations hydroélectriques. Bull. Fr. Pisc., 312-313, $94 \mathrm{p}$.

MONTEN E., 1985. Fish and turbines. Fish injuries during passage through power station turbines. Vattenfall, Stockholm, $111 \mathrm{p}$.

MONTREAL ENGINEERING COMPANY, 1981. Fish mortality as a function of the hydraulic properties of turbines. Can. Electr. Assoc., Res. and Dev., Rep. G-144, 75 p. 
NIETZEL D.A., CLUNET T.J., ABERNETHY C.S., 1990. Evaluation of rotary drum screens used to project juvenile salmonids in the Yakima river basin, Washington, USA, Proc. Int. Symp. on fishways, Gifu, Japan, 523-529.

RAINEY W.S., 1990. Cylindrical drum screens designs for juvenile fish protection at two large diversions. Proc. Int. Symp. on fishways, Gifu, Japan, 143-150.

RUGGLES C.P., 1980. A review of the downstream migration of atlantic salmon. Freshwater and Anadromous Div., Resource Branch Dept. of Fisheries and Oceans, Halifax, Nova Scotia, Can. Tech. Rep. of Fisheries and Aquatic Sci. 952, 39 p.

RUGGLES C.P., 1992. What's new in downstream fish passage ? $4^{\text {th }}$ Int. Atlantic Salmon Symp. St Andrews, New Brunswick, Canada, 22 p.

RUGGLES C.P., MURRAY D.G., 1983. A review of fish response to spillways. Freshwater and Anadromous Div., Resource Branch Dept. of Fisheries and Oceans, Halifax, Nova Scotia, Can. Tech. Rep. of Fisheries and Aquatic Sci. 1172, 30 p.

SAUNDERS P.W., 1992. Downstream migration of atlantic salmon smolts at PSNH hydroelectric stations on the Merrimack and Pemigewasset rivers. Envir. Dept., Public Serv. Comp. of New Hampshire, Manchester, 80 p.

TAYLOR R.E., KYNARD B., 1985. Mortality of juvenile american shad and blueback herring passed through a low-head Kaplan Hydro-electric turbine. Tran. Am. Fish. Soc., 114: 430-435.

WILLIAMS, J.G., 1990. Water velocity in relation to fish behavior in the design of screens for diversion of juvenile salmonids from turbines at hydroelectric dams on the Columbia river, USA. Proc. Int. Symp. on fishways, Gifu, Japan, 137-142. 


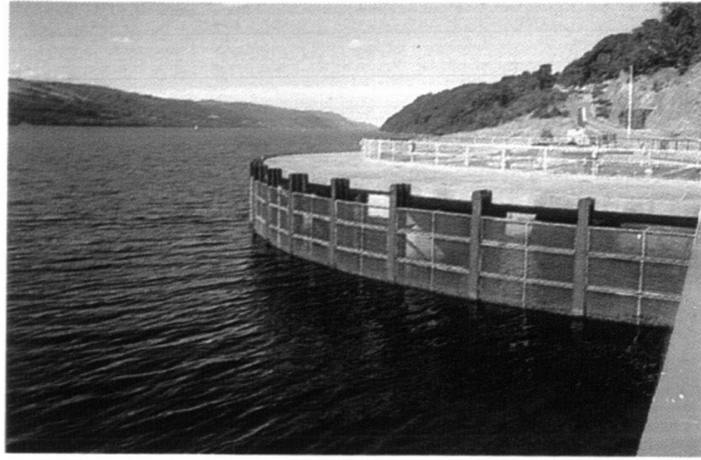

Photo 1 : Grilles fines sur une prise d'eau en Ecosse.

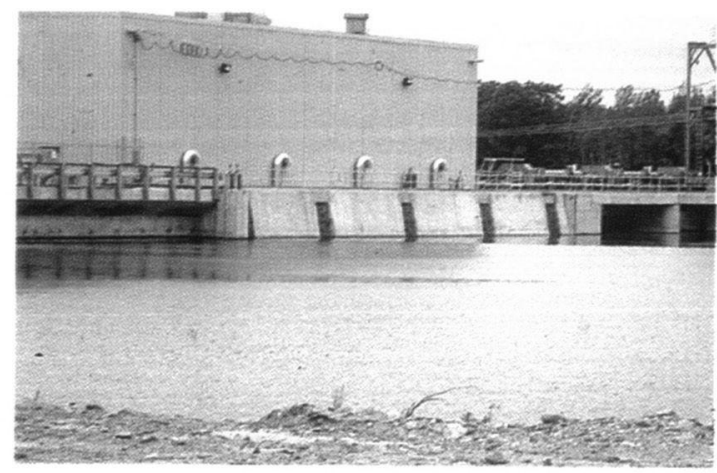

Photo 3 : Exutoires de dévalaison situés au. dessus de la prise d'eau des turbines à la centrale de West-Enfield (Maine, USA).

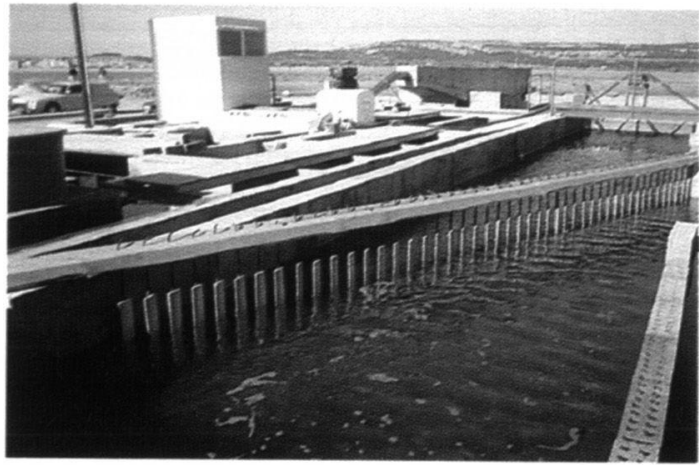

Photo 2 : Ecran hydrodynamique expérimental.

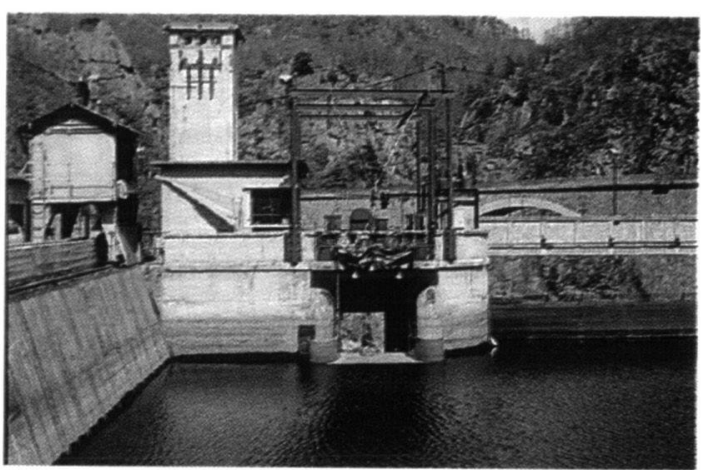

Photo 4 : Exutoire de dévalaison à la prise d'eau de Poutès sur l'Allier.

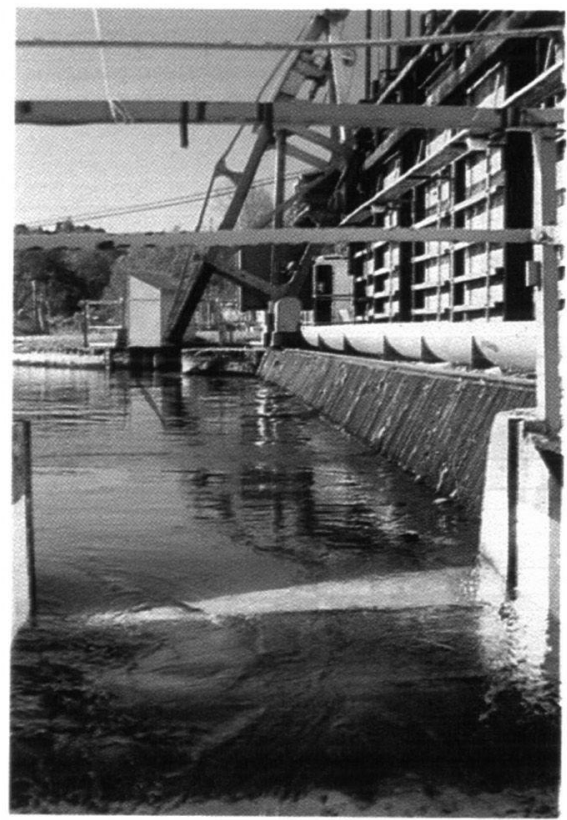

Photo 5 : Exutoire de dévalaison à la centrale d'Halsou sur la Nive. 
Bull. Fr. Pêche Piscic. (1992) 326-327 : 177-206 - 177 -

\section{ANNEXES}

FICHES PASSES A POISSONS 


\title{
PASSE A POISSONS A L'USINE DE BERGERAC
}

\author{
(VILLE DE BERGERAC - 24)
}

\section{CARACTÉRISTIQUES DE L'AMÉNAGEMENT ET HYDROLOGIE}

Cours d'eau : Dordogne

Module : $265 \mathrm{~m}^{3} / \mathrm{s}$

Etiage (DCE 355) : $30 \mathrm{~m}^{3} / \mathrm{s}$

Rôle du barrage : hydroélectricité

Débit d'équipement : $57 \mathrm{~m}^{3} / \mathrm{s}$

Cote NGF du plan d'eau amont : 18.32

Cote NGF du niveau d'eau aval : 14.35 (étiage)

Chute maximale : 3.97 m environ

Variation du niveau amont : 2 m environ

aval : $4 \mathrm{~m}$ environ

\section{TYPE DE PASSE : passe à bassins à deux fentes verticales}

Dénivellation entre bassins : $0.30 \mathrm{~m}$

Nombre de chutes : 14

Dimensions des bassins courants : $6.00 \mathrm{~m} \times 4.15 \mathrm{~m}$

Largeur des fentes : $2 \times 0.55 \mathrm{~m}$

Tirant d'eau moyen (étiage) : $1.80 \mathrm{~m}$

Débit passe : de $2.2 \mathrm{~m}^{3} / \mathrm{s}$ (étiage) à $6.0 \mathrm{~m}^{3} / \mathrm{s}$

Débit d'attrait : variable de $0 \mathrm{~m}^{3} / \mathrm{s}$ (étiage) à $5.0 \mathrm{~m}^{3} / \mathrm{s}$

Largeur entrée : $2.0 \mathrm{~m}$

Largeur sorties : $2 \times 1.30 \mathrm{~m}$

Coût : 9000 KF (1984)

\section{COMMENTAIRES}

Le dispositif de franchissement est destiné aux grands migrateurs (saumon, alose, truite de mer, lamproie, anguille) ainsi qu'aux espèces holobiotiques. La passe à poissons est équipée d'un piège et d'une vitre de comptage dans sa partie aval.

Lors de la mise en service en 1985, des opérations de piégeage ont été conduites entre le mois de mai et décembre : plus de 2000 aloses, 24 saumons, 51 truites de mer et plusieurs milliers d'individus d'autres espèces ont été capturés dans le piège. Le piège ne peut être cependant armé en période du pic de migration de l'alose sans risque d'induire des mortalités notables sur cette espèce. Le dispositif est considéré comme très efficace pour l'alose (plus de 8000 aloses ont été contrôlées à l'ascenseur de Tuilières situé à une quinzaine de kilomètres en amont de Bergerac).

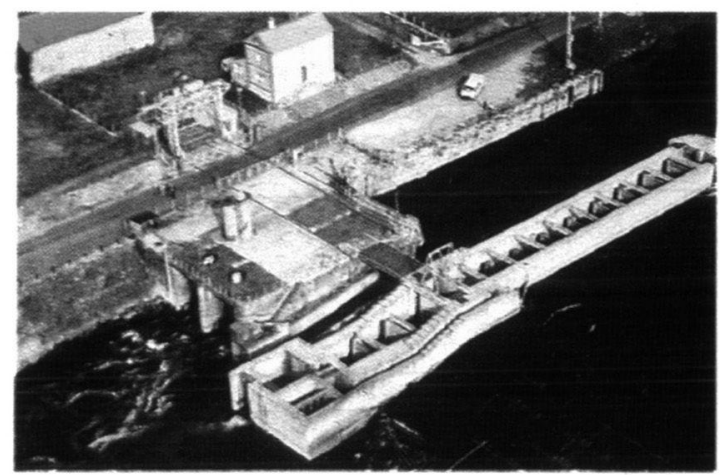



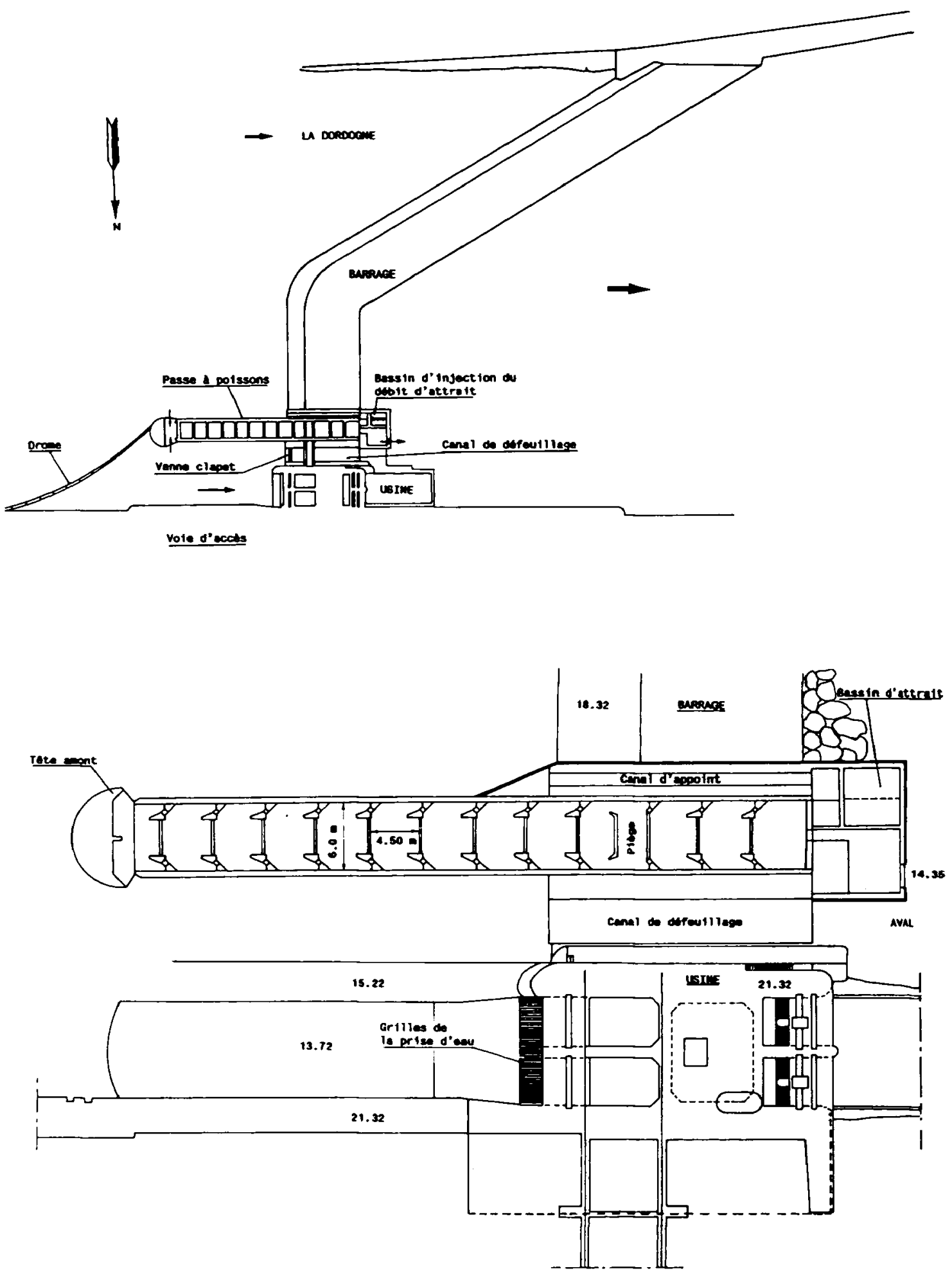


\section{PASSE A POISSONS A L'USINE DU RAMIER DU CHATEAU}

(VILLE DE TOULOUSE - 31)

\section{CARACTÉRISTIQUES DE L'AMÉNAGEMENT ET HYDROLOGIE}

Cours d'eau : Garonne

Module : $190 \mathrm{~m}^{3} / \mathrm{s}$

Etiage (DCE 355) : $25 \mathrm{~m}^{3} / \mathrm{s}$

Rôle du barrage : hydroélectricité

Longueur du canal d'amenée : $105 \mathrm{~m}$

Débit d'équipement : $160 \mathrm{~m}^{3} / \mathrm{s}$

Cote NGF du plan d'eau amont : 136.77

Cote NGF du niveau aval : 132.45

Chute maximale : $4.32 \mathrm{~m}$ environ

Variation du niveau amont : $0.60 \mathrm{~m}$

aval : $1.80 \mathrm{~m}$

TYPE DE PASSE : passe à bassins successifs à fente verticale

Dénivellation entre bassins : $0.285 \mathrm{~m}$

Nombre de chutes : 15

Dimensions des bassins courants : $4.50 \mathrm{~m}$ (longueur)

$2.50 \mathrm{~m}$ (largeur)

Largeur des fentes : $0.50 \mathrm{~m}$

Tirant d'eau moyen : $1.80 \mathrm{~m}$

Débit passe : $1.2 \mathrm{~m}^{3} / \mathrm{s}$

Débit d'attrait : variable de $0.200 \mathrm{~m}^{3} / \mathrm{s}$ à plus de $1.0 \mathrm{~m}^{3} / \mathrm{s}$

Largeur entrée : $1.20 \mathrm{~m}$

Coût : $3700 \mathrm{KF}$ (1987)

\section{COMMENTAIRES}

Les espèces concernées par l'amite de mer, anguille) ainsi que les espèces holobiotiques.

La passe à poissons est équipée d'un dispositif de piégeage permettant de contrôler la migration d'avalaison et de montaison.

Les opérations de suivi réalisées depuis la mise en service dénotent un bon fonctionnement et une bonne attractivité du dispositif, en particulier pour l'alose.

La sortie de la passe à poissons, située à proximité des grilles de la prise d'eau, permet d'attirer un faible pourcentage des poissons dévalants.
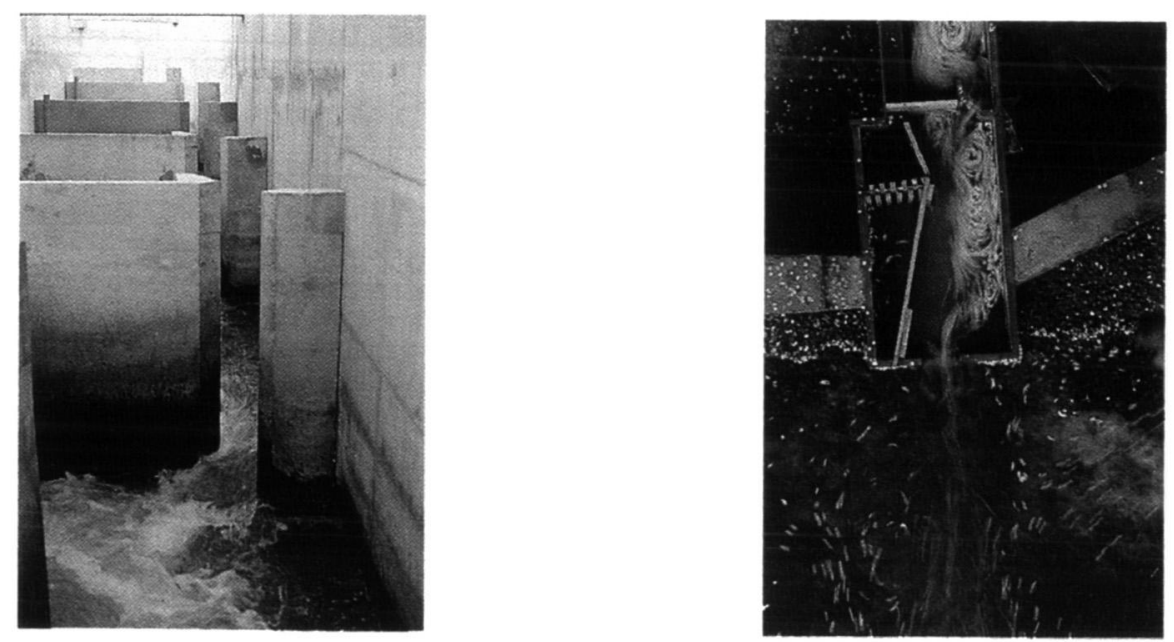


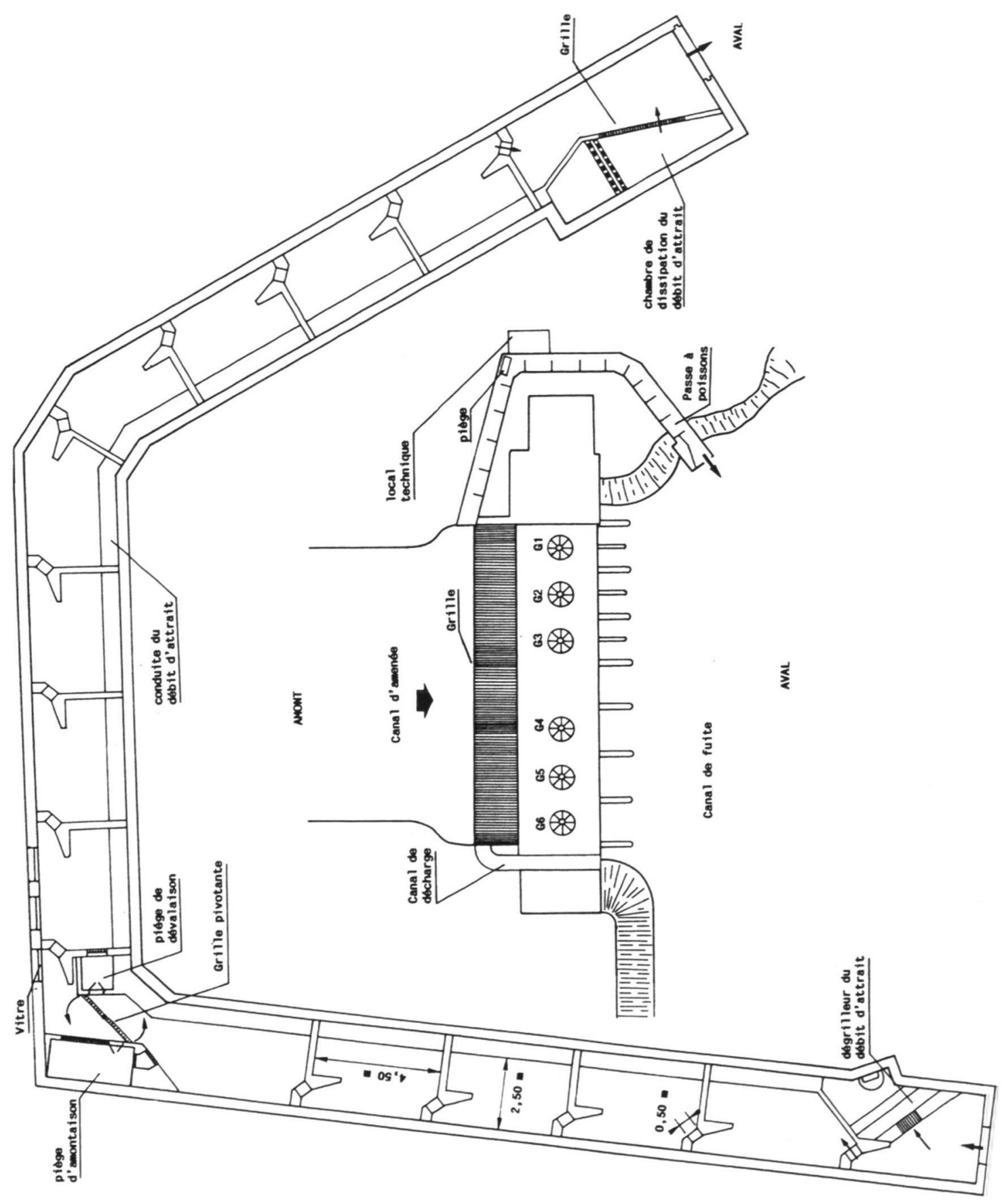




\section{PASSE A POISSONS AU BARRAGE DE LAS RIVES}

(COMMUNES DE VARILHES ET SAINT JEAN DE VERGES - 09)

\section{CARACTÉRISTIQUES DE L'AMÉNAGEMENT ET HYDROLOGIE}

Cours d'eau : Ariège

Module interannuel : $45.5 \mathrm{~m}^{3} / \mathrm{s}$

Débit d'étiage (DCE 355) : $15.2 \mathrm{~m}^{3} / \mathrm{s}$

Débit réservé : $1.14 \mathrm{~m}^{3} / \mathrm{s}$

Rôle du barrage : hydroélectricité

Longueur de la dérivation : 500 mètres environ

Largeur de crête : $120.0 \mathrm{~m}$

Débit d'équipement de l'usine : $25 \mathrm{~m}^{3} / \mathrm{s}$

Cote NGF barrage : $333.50 \mathrm{~m}$

Cote NGF aval : $329.30 \mathrm{~m}$

Chute maximale : $4.20 \mathrm{~m}$ environ

Variation des niveaux amont et aval : $0.50 \mathrm{~m}$ en amont et $1.20 \mathrm{~m}$ en aval (entre l'étiage et $90 \mathrm{~m}^{3} / \mathrm{s}$ )

TYPE DE PASSE : bassins successifs à échancrure latérale et à orifice noyé et prébarrage aval

- Bassins successits :

Dénivellation entre bassins : $0.30 \mathrm{~m}$

Nombre de chutes : 12

Dimensions des bassins courants : $3.20 \mathrm{~m}$ (longueur)

$1.90 \mathrm{~m}$ (largeur)

Largeur des échancrures : $0.45 \mathrm{~m}$ (sauf échancrure amont : $0.50 \mathrm{~m}$ )

Charge sur échancrure courante (étiage) : $0.70 \mathrm{~m}$

Dimensions des orifices : $0.30 \mathrm{~m} \times 0.30 \mathrm{~m}$ (sauf paroi amont sans orifice)

Tirant d'eau moyen : $1.45 \mathrm{~m}$

Débit : de $0.5 \mathrm{~m}^{3} / \mathrm{s}$ (étiage) à $0.82 \mathrm{~m}^{3} / \mathrm{s}$

Puissance dissipée : 170 watts $/ \mathrm{m}^{3}$ (étiage) à 210 watts $/ \mathrm{m}^{3}$

Largeur entrée (aval) : $0.80 \mathrm{~m}$

Largeur sortie : $1.50 \mathrm{~m}$

\section{- Prébarrage aval :}

Cote de l'échancrure : $329.39 \mathrm{NGF}$

Largeur ael'échancrure : $2.0 \mathrm{~m}$

Chute en étiage : $0.60 \mathrm{~m}$

Cote des murs latéraux : $329.90 \mathrm{~m}$

Coût : 800 KF (1987)

\section{COMMENTAIRES}

La forme particulière de la passe, repliée sur elle-même, permet une bonne intégration du dispositif dans la pointe amont du barrage. Un prébarrage permet de rattraper la chute totale et de garantir un niveau minimum à l'entrée de la passe. 

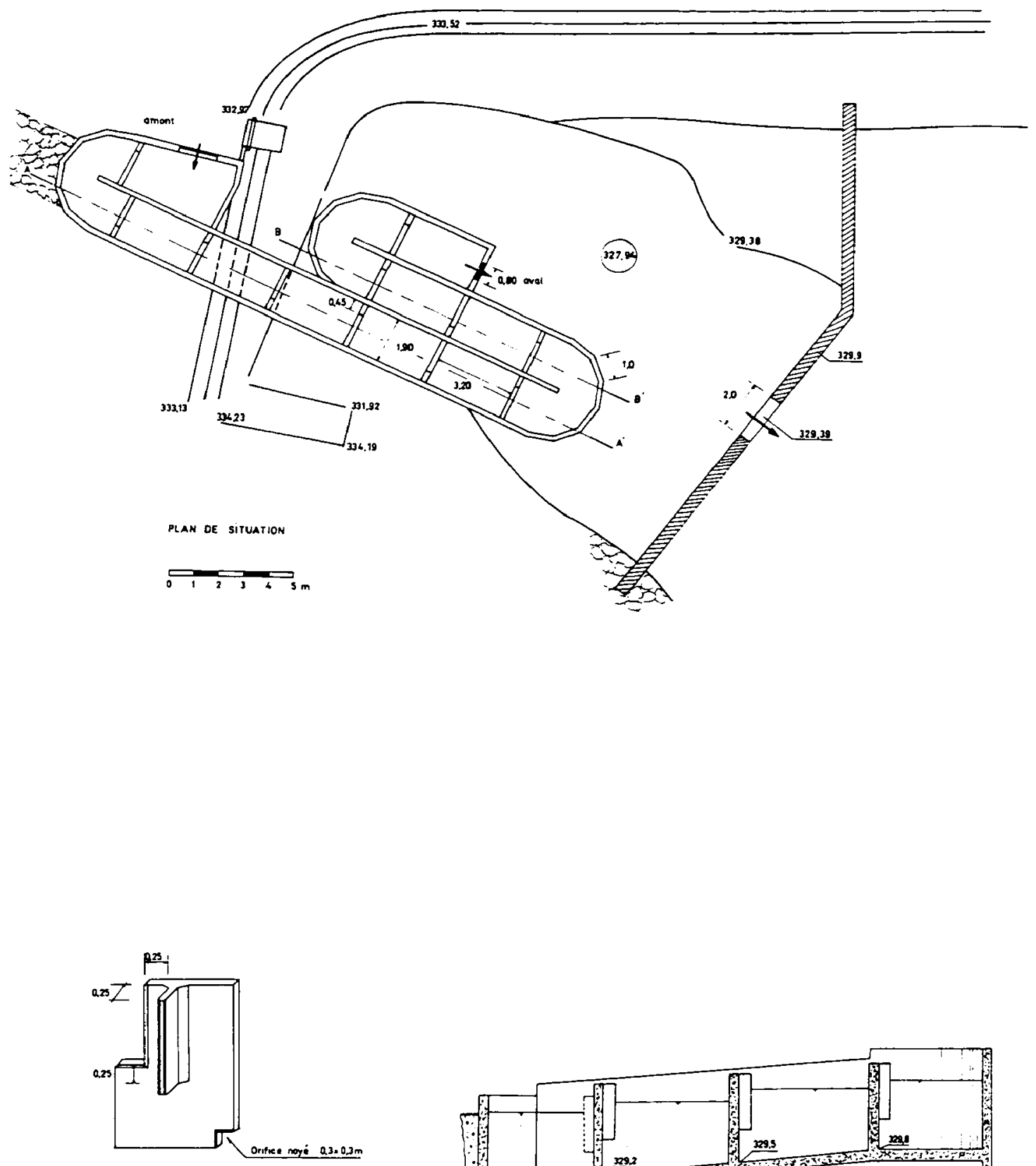

Qetal diune cloison
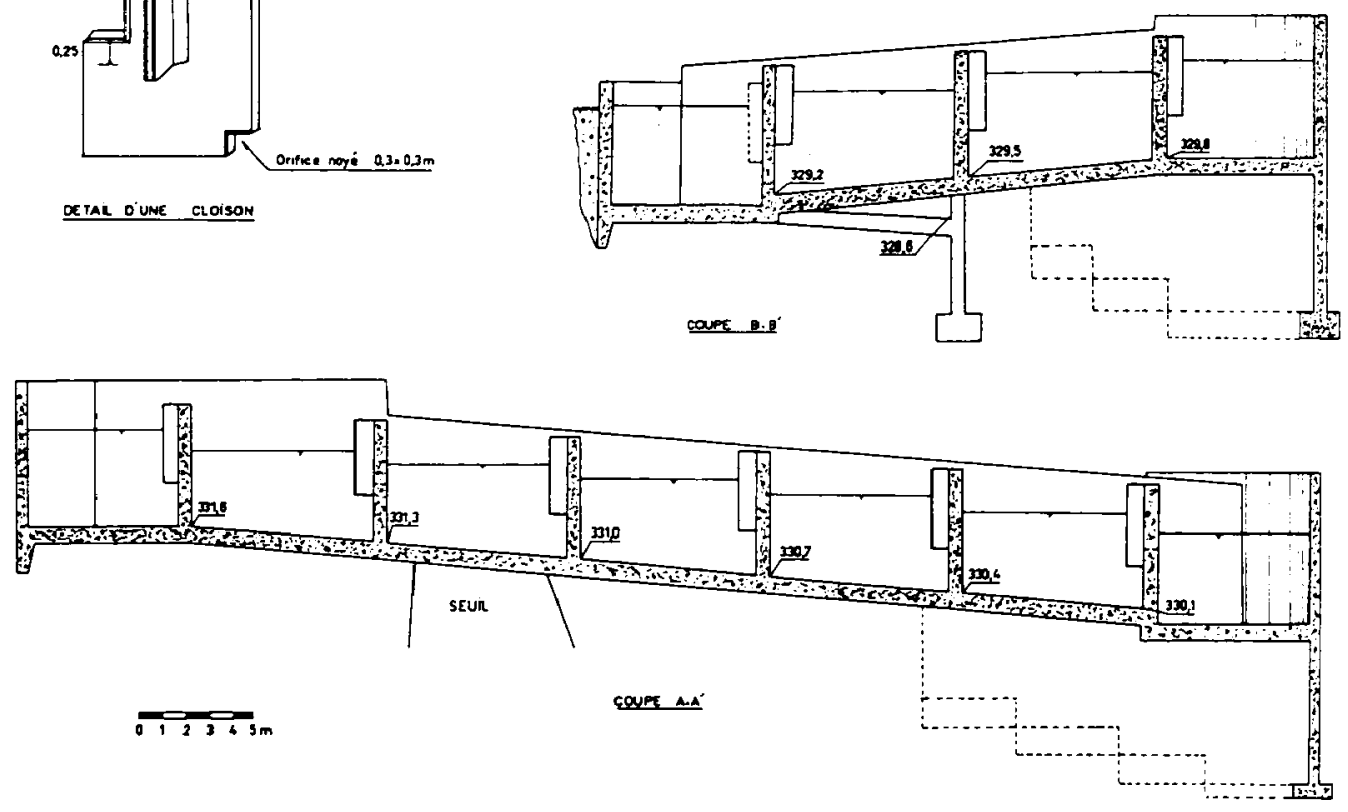
Bull. Fr. Pêche Piscic. (1992) 326-327 : 177-206 - 184 -
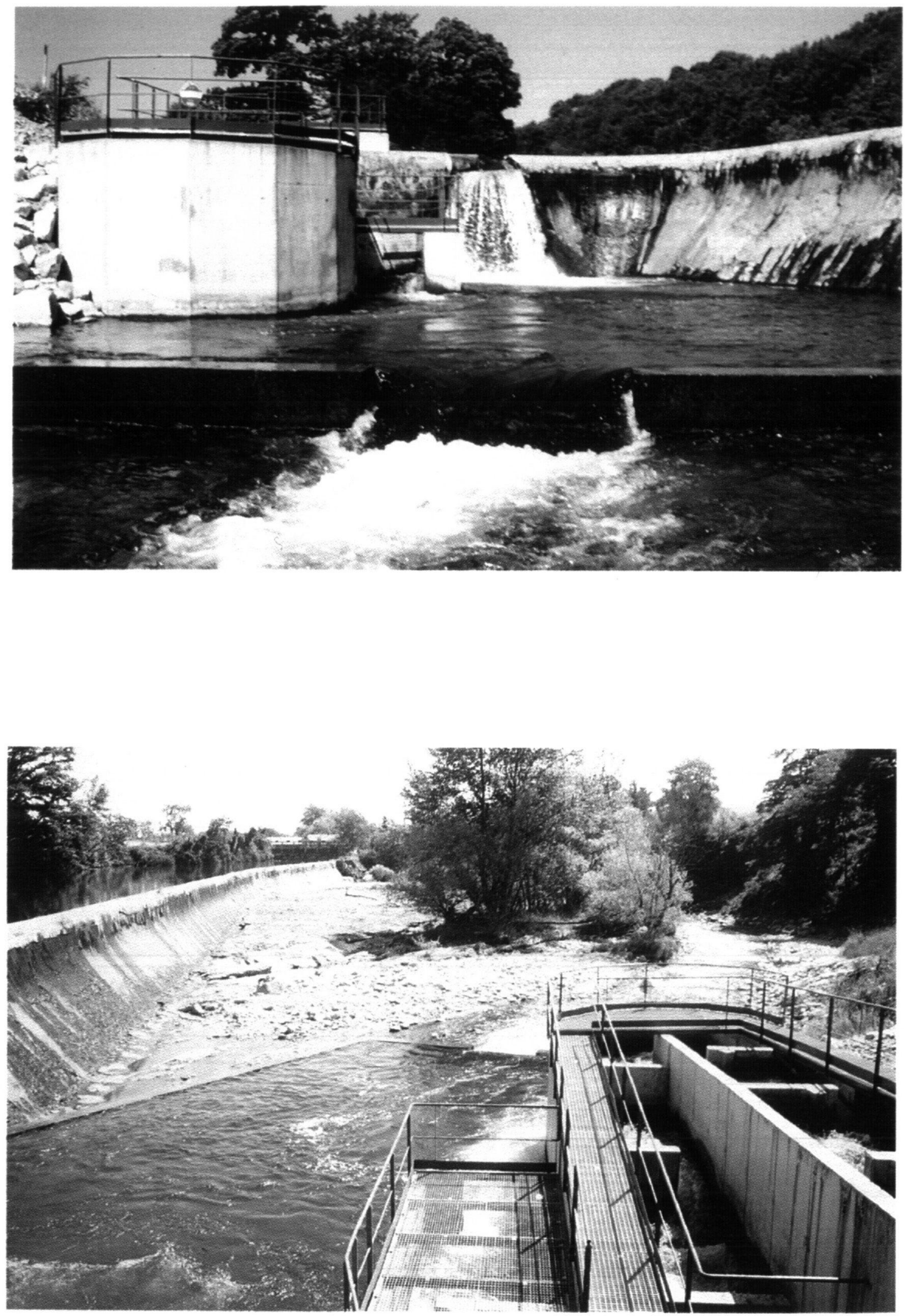


\section{PASSE A POISSONS AU BARRAGE DE LIBARRENX (64)}

\section{CARACTERISTIQUES DE L'AMENAGEMENT ET HYDROLOGIE}

Cours d'eau: Gave de Mauléon

Module : $27 \mathrm{~m}^{3} / \mathrm{s}$

Etiage (DCE 355) : $3.8 \mathrm{~m}^{3} / \mathrm{s}$

Débit réservé : $0.550 \mathrm{~m}^{3} / \mathrm{s}$

Rôle du barrage : hydroélectricité

Longueur de la dérivation : 300 m environ

Longueur de crête : 79 m

Débit d'équipement de l'usine : $7 \mathrm{~m}^{3} / \mathrm{s}$

Cote NGF barrage : 149.08

Cote NGF étiage : 147.3

Chute maximale : 1.80 m environ

Variation des niveaux amont et aval (entre étiage et $80 \mathrm{~m}^{3} / \mathrm{s}$ ) : $0.80 \mathrm{~m}$ environ

\section{TYPE DE PASSE : bassins successifs à échancrure latérale et à orifice noyé}

Dénivellation entre bassins : $0.30 \mathrm{~m}$

Nombre de chutes : 6

Dimensions des bassins courants : $3 \mathrm{~m}$ (longueur)

Largeur des échancrures : $0.50 \mathrm{~m}$

$1.8 \mathrm{~m}$ (largeur)

Charge sur échancrure (étiage) : $0.60 \mathrm{~m}$

Dimensions des orifices : $0.30 \mathrm{~m} \times 0.30 \mathrm{~m}$

Tirant d'eau moyen (étiage) : $1.50 \mathrm{~m}$

Débit : de $0.5 \mathrm{~m}^{3} / \mathrm{s}$ (étiage) à $1.1 \mathrm{~m}^{3} / \mathrm{s}$

Puissance dissipée : de 170 watts $/ \mathrm{m}^{3}$ (étiage) à 260 watts $/ \mathrm{m}^{3}$

Largeur entrée : $0.70 \mathrm{~m}$ calée à 146.80

Largeur sortie : $1.20 \mathrm{~m}$ calée à 148.00

Coût : 350 KF (1986)

\section{COMMENTAIRES}

L'entrée de la passe a été implantée dans le chenal principal d'écoulement à l'aval, à quelques mètres (environ $3.5 \mathrm{~m}$ ) du pied du barrage. La passe a été repliée sur elle-même de façon à perturber le moins possible l'écoulement en amont en période de fortes eaux, la prise d'eau du canal d'amenée étant située à l'intérieur d'une courbe de la rivière. La tête amont arrondie de la passe et la situation latérale de la sortie réduisent les problèmes d'entretien.

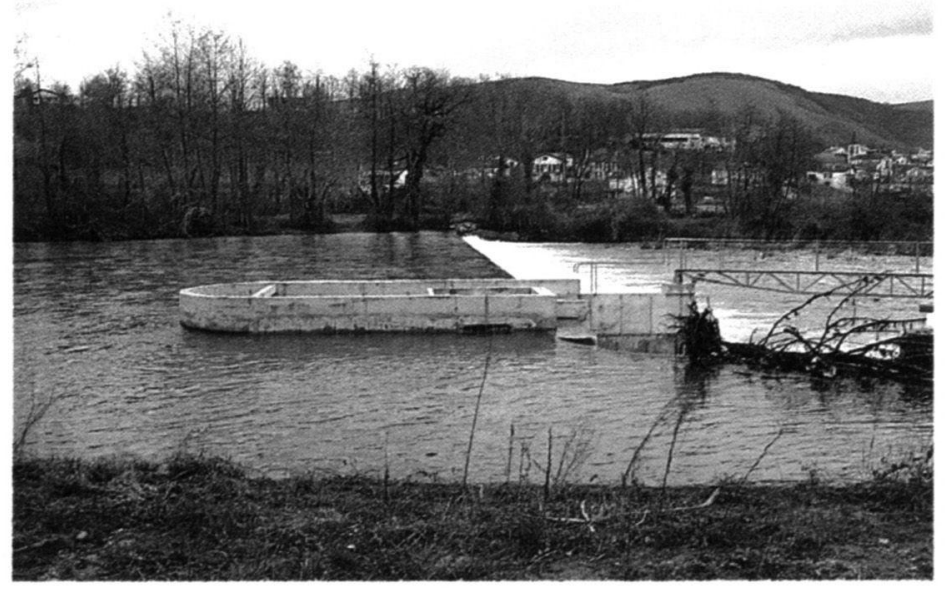


Bull. Fr. Pêche Piscic. (1992) 326-327: 177-206 - 186 -
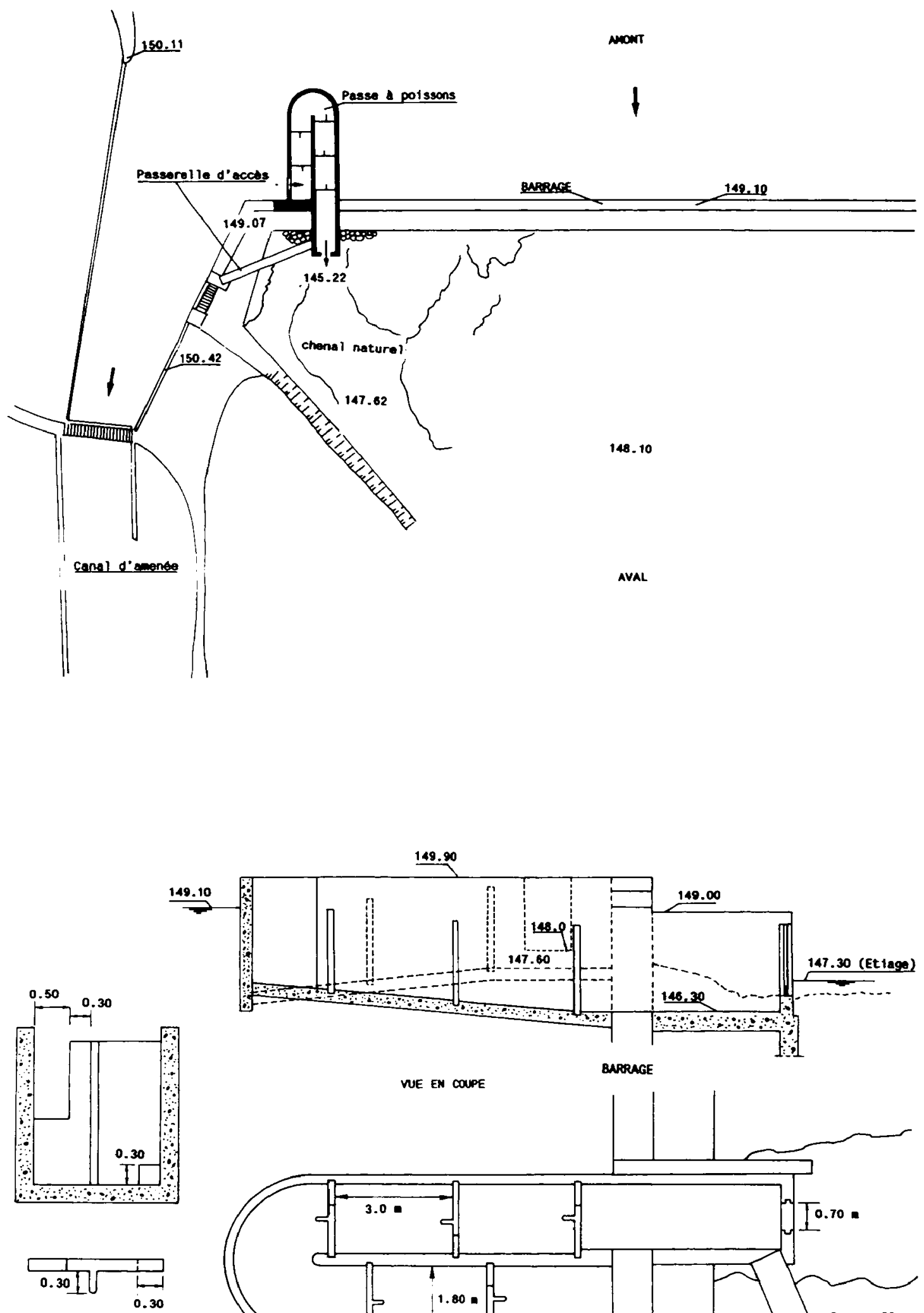

OETAIL D'UNE ECHUNCRURE

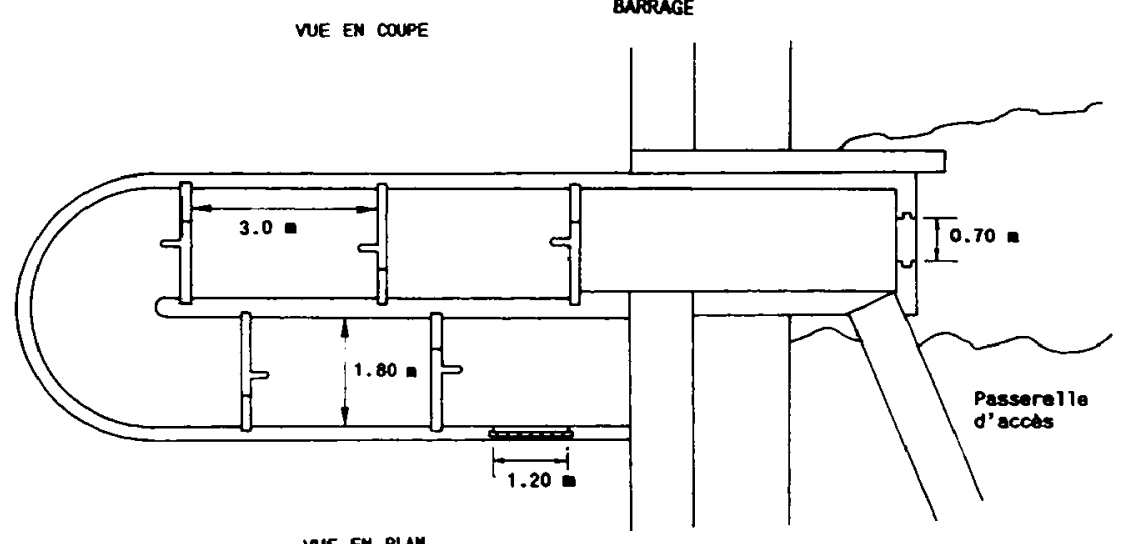

NUE EN PLN 


\section{PASSE A POISSONS AU BARRAGE DES CABANNES}

(COMMUNE LES CABANNES - 09)

\section{CARACTÉRISTIQUES DE L'AMÉNAGEMENT ET HYDROLOGIE}

Cours d'eau : Ariège

Module : $11.0 \mathrm{~m}^{3} / \mathrm{s}$

Etiage : $1.7 \mathrm{~m}^{3} / \mathrm{s}$

Débit réservé : $0.440 \mathrm{~m}^{3} / \mathrm{s}$ jusqu'au renouvellement de l'autorisation en 1994

Rôle du barrage : hydroélectricité

Longueur de crête : $46 \mathrm{~m}$

Débit d'équipement de l'usine : $12 \mathrm{~m}^{3} / \mathrm{s}$

Cote NGF barrage : 537.59

Cote NGF plan d'eau aval (étiage) : 536.06

Chute maximale : $1.53 \mathrm{~m}$

Variations des niveaux d'eau amont et aval : $0.50 \mathrm{~m}$ et $0.60 \mathrm{~m}$ environ

\section{TYPE DE PASSE : prébarrages}

Dénivellation entre bassins : $0.50 \mathrm{~m}$

Nombre de chutes : 3

Dimensions des bassins : $(4 \mathrm{~m} \times 9 \mathrm{~m})$ et $(5 \mathrm{~m} \times 5.5 \mathrm{~m})$

Largeur des échancrures : $1.0 \mathrm{~m}$

Charge sur échancrure (étiage) : $0.40 \mathrm{~m}$

Tirant d'eau moyen : $1.00 \mathrm{~m}$

Débit (étiage) : $0.440 \mathrm{~m}^{3} / \mathrm{s} ; 1.00 \mathrm{~m}^{3} / \mathrm{s}$ à partir de 1994 .

Puissance dissipée : 60 watts $/ \mathrm{m}^{3}$ (étiage) à 150 watts $/ \mathrm{m}^{3}\left(45 \mathrm{~m}^{3} / \mathrm{s}\right)$

\section{COMMENTAIRES}

Située dans l'angle amont du barrage et contre la rive droite, la passe a nécessité peu de travaux de génie civil. Le dispositif a été calé pour pouvoir fonctionner avec un débit de $1.0 \mathrm{~m}^{3} / \mathrm{s}$ lors du renouvellement de l'autorisation en 1994.
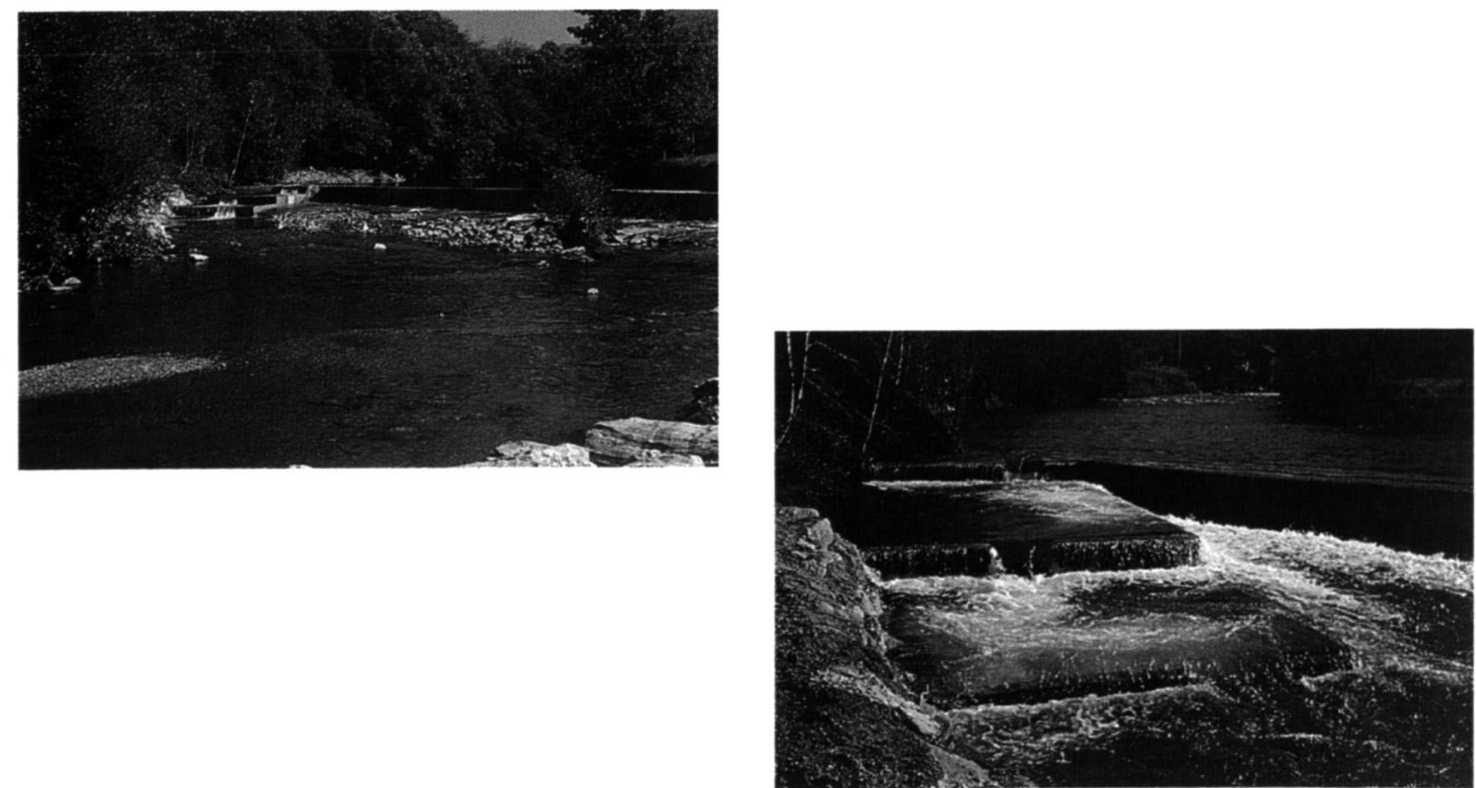


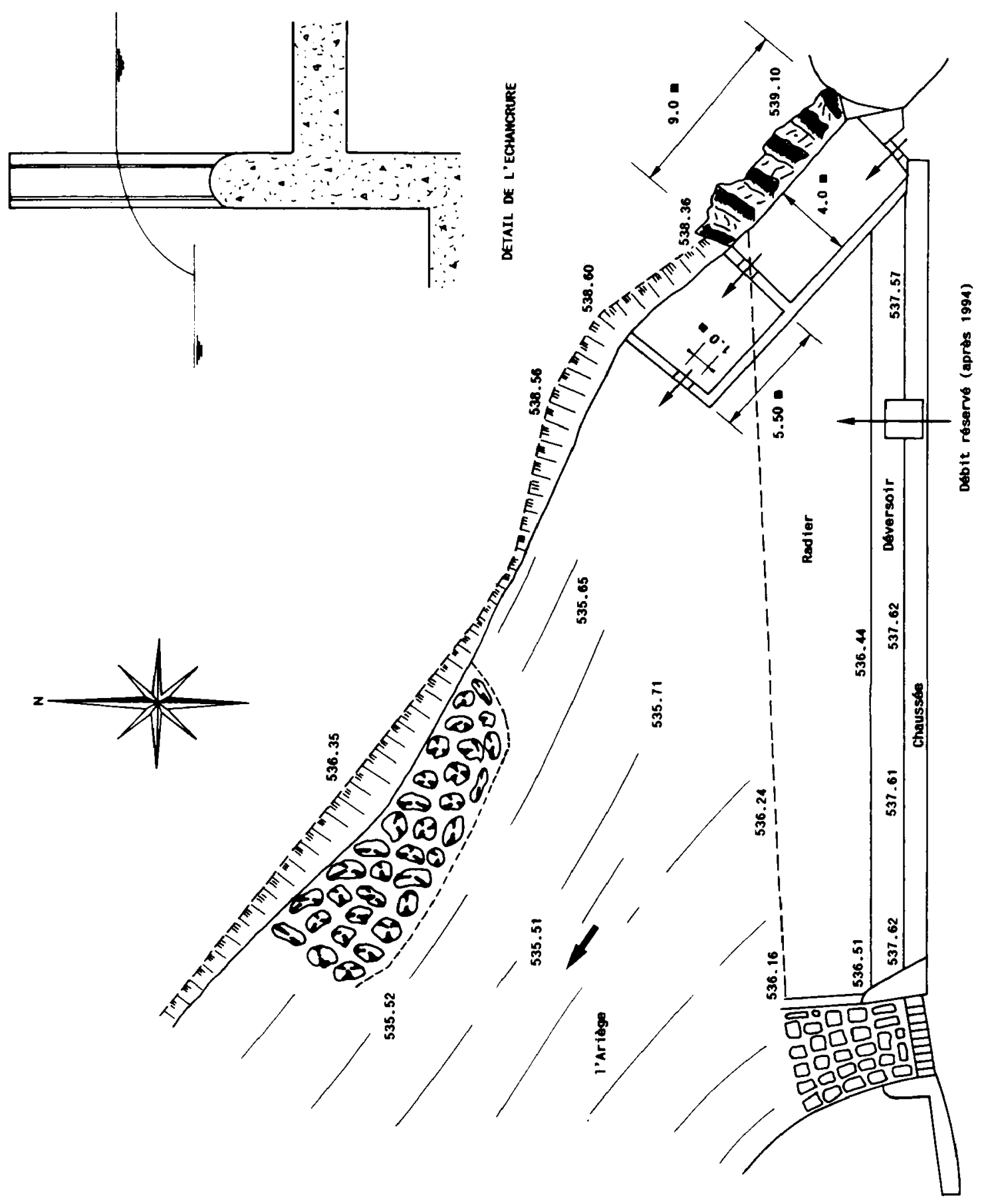




\section{PASSE A POISSONS AU BARRAGE DE TESSY SUR VIRE (50)}

\section{CARACTÉRISTIQUES DE L'AMÉNAGEMENT ET HYDROLOGIE}

Cours d'eau : Vire

Module : $9.0 \mathrm{~m}^{3} / \mathrm{s}$

Débit résenvé : $900 \mathrm{l} / \mathrm{s}$

Rôle du barrage : hydroélectricité

Longueur de la dérivation : usine rive droite : néant

usine rive gauche : $300 \mathrm{~m}$

Longueur crête déversoir : $30 \mathrm{~m}$

Débit d'équipement: usine rive droite : $4+3=7 \mathrm{~m}^{3} / \mathrm{s}$

usine rive gauche : $6 \mathrm{~m}^{3} / \mathrm{s}$

Cote NGF plan d'eau amont : 37.54

Cote NGF aval étiage : 34.54

Chute maximale : $3.00 \mathrm{~m}$

Variation du niveau amont : $0.25 \mathrm{~m}$

aval : environ $0.40 \mathrm{~m}$ pour $\mathrm{Q}=20 \mathrm{~m}^{3} / \mathrm{s}$

TYPE DE PASSE : ralentisseurs suractifs (2 volées avec bassin de repos)

Longueur des volées : $10 \mathrm{~m}$

Pente du radier : $15 \%$

Largeur du canal : $1.50 \mathrm{~m}$

Hauteur des ralentisseurs : $0.125 \mathrm{~m}$

Dimensions du bassin de repos : $4 \mathrm{~m} \times 2.40 \mathrm{~m}$, tirant d'eau à l'étiage : $1.50 \mathrm{~m}$

Dénivelé rattrapé : $3 \mathrm{~m}$ ( $1.50 \mathrm{~m}$ par volée)

Débit d'alimentation à l'étiage : $600 \mathrm{l} / \mathrm{s}$

\section{COMMENTAIRES}

Le site est équipé de deux microcentrales :

- une usine avec une turbine de $6 \mathrm{~m}^{3} / \mathrm{s}$ en rive gauche, dans la dérivation d'une ancienne écluse de navigation,

- une microcentrale avec deux turbines (4 et $3 \mathrm{~m}^{3} / \mathrm{s}$ ) en rive droite au niveau du barrage.

La passe à poissons est installée sur ce dernier bras. Il est prescrit au permissionnaire de n'utiliser la turbine rive gauche que lorsque les deux autres turbines fonctionnent à leur débit nominal pour éviter aux migrateurs de s'engager dans une voie sans issue.

La dévalaison est possible sur le déversoir dans le bras rive droite. Un exutoire avec une goulotte aboutissant dans le bras de décharge est installé au niveau des grilles de la prise d'eau de la microcentrale rive gauche.

En raison de la situation de la passe à poissons (rive droite du déversoir, accès difficile), l'entretien du dispositif pose quelques problèmes malgré l'existence d'une protection amont. 
$\stackrel{8}{*}$

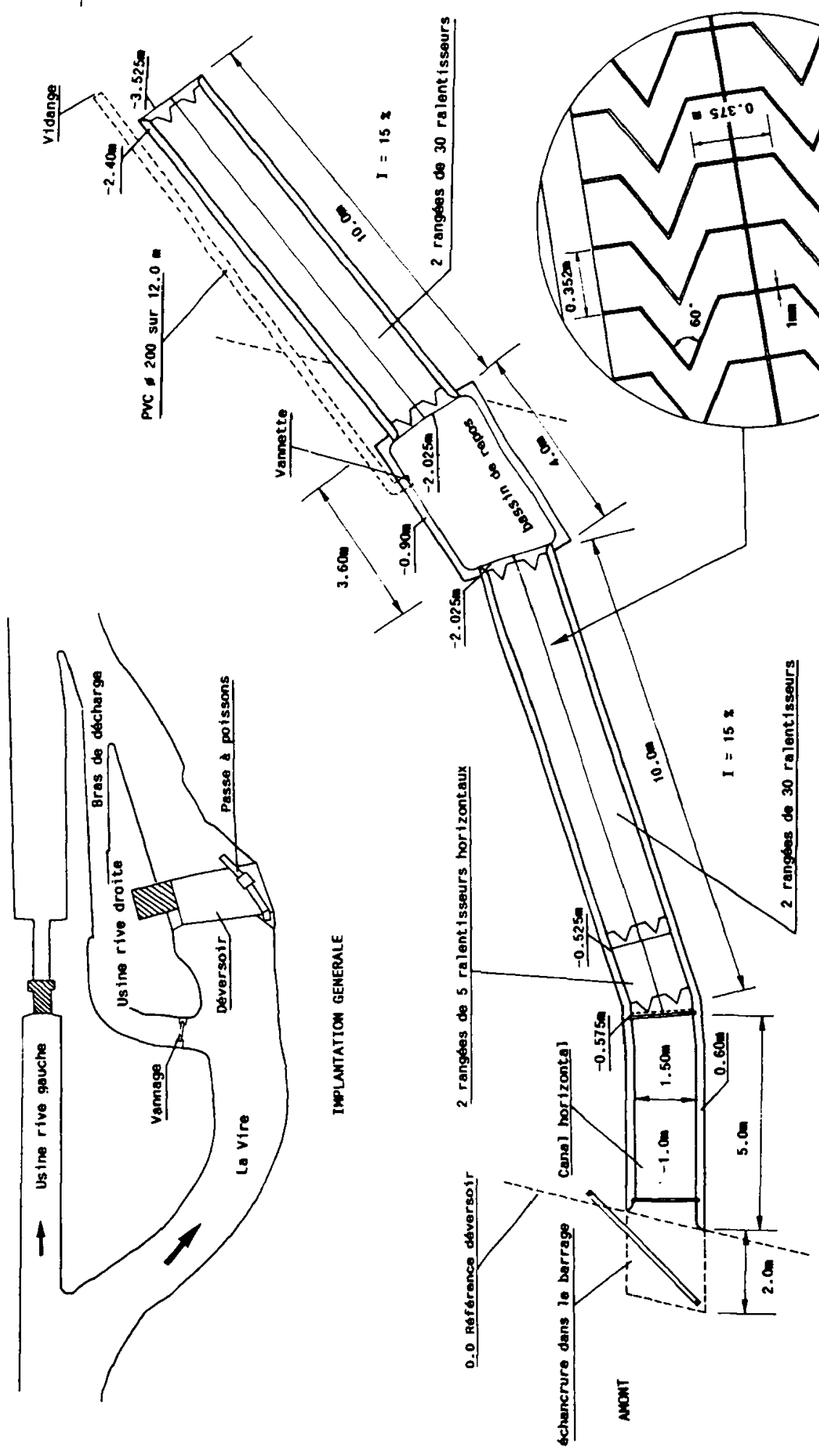

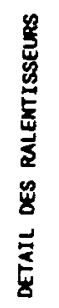


Bull. Fr. Pêche Piscic. (1992) 326-327 : 177-206 — 191 —
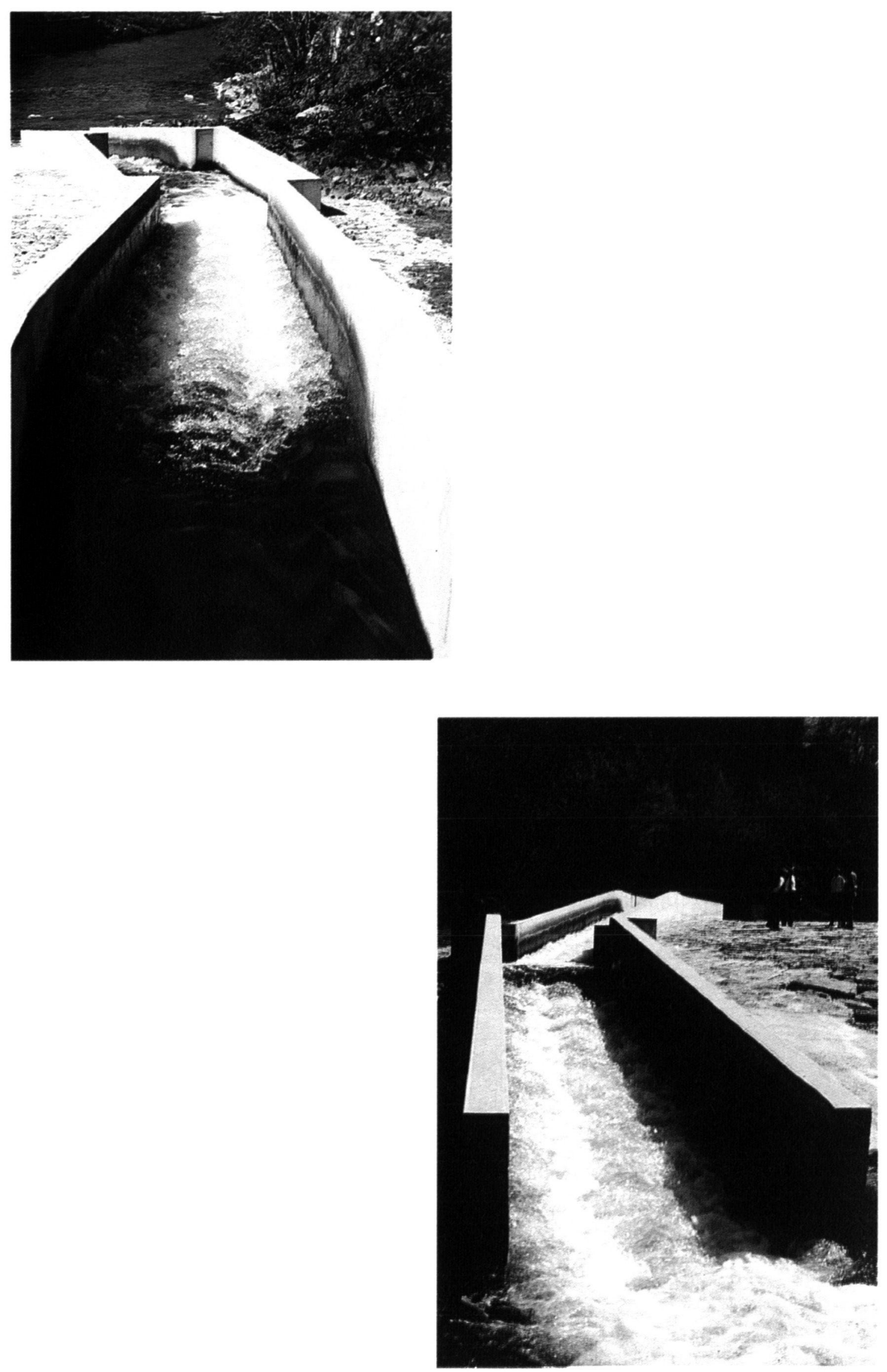


\section{PASSE A POISSONS AU BARRAGE DE GOAS VILINIC}

(COMMUNE DE PONTRIEUX- 22)

\section{CARACTÉRISTIQUES DE L'AMÉNAGEMENT ET HYDROLOGIE}

\section{Cours d'eau : Trieux}

Module : $6.7 \mathrm{~m}^{3} / \mathrm{s}$

Etiage (VCN 30 quinquennal) : $0.68 \mathrm{~m}^{3} / \mathrm{s}$

Débit réservé : réglementation en cours, actuellement surplus non utilisé pour les éclusées. Rôle du barrage : navigation dans le port de Pontrieux

Longueur de la dérivation : $700 \mathrm{~m}$

Longueur de crête : $75 \mathrm{~m}$, avec volets mobiles de $\mathrm{h}=0.70 \mathrm{~m}$ sur toute la longueur

Cote NGF plan d'eau amont : 4.5

Cote NGF aval (soumis à la marée) : 0.50 minimum

Chute maximale : $4.00 \mathrm{~m}$

Variation du niveau amont : de 4.5 à 4.7 (régulation par volets mobiles) aval : de 0.50 à 4.5 suivant la marée

TYPE DE PASSE : ralentisseurs plans (2 volées avec bassin de repos) et prébarrage aval

Longueur des volées: $7.50 \mathrm{~m}$ environ

Largeur du canal : $0.95 \mathrm{~m}$

Pente du radier : $20 \%$

Débit de calage : $0.350 \mathrm{~m}^{3} / \mathrm{s}$

Dimensions du bassin de repos : $L=3 \mathrm{~m} \mathrm{I}=2 \mathrm{~m}$ Tirant d'eau $>1.50 \mathrm{~m}$

Dénivelé rattrapé par chaque volée : $1.50 \mathrm{~m}$ environ

Dénivelé restant au niveau du prébarrage : $1.00 \mathrm{~m}$

\section{COMMENTAIRES :}

Les espèces concernées par l'aménagement sont le saumon et la truite de mer.

Le dispositif de franchissement a été construit principalement en amont du barrage de telle sorte que l'entrée pour le poisson soit située au pied même du déversoir, dans l'angle aigu amont (rive droite).

Un prébarrage maintient un niveau d'eau constant au pied de la volée aval à marée basse. La chute maximale au niveau du prébarrage est de $1.20 \mathrm{~m}$. Elle diminue rapidement dès le début de la marée montante.

Le volet mobile situé en rive droite est manoeuvré en priorité pour renforcer l'attractivité de la passe à poissons et favoriser la dévalaison des smolts dans cette zone (chute dans le matelas d'eau constitué par le prébarrage). 

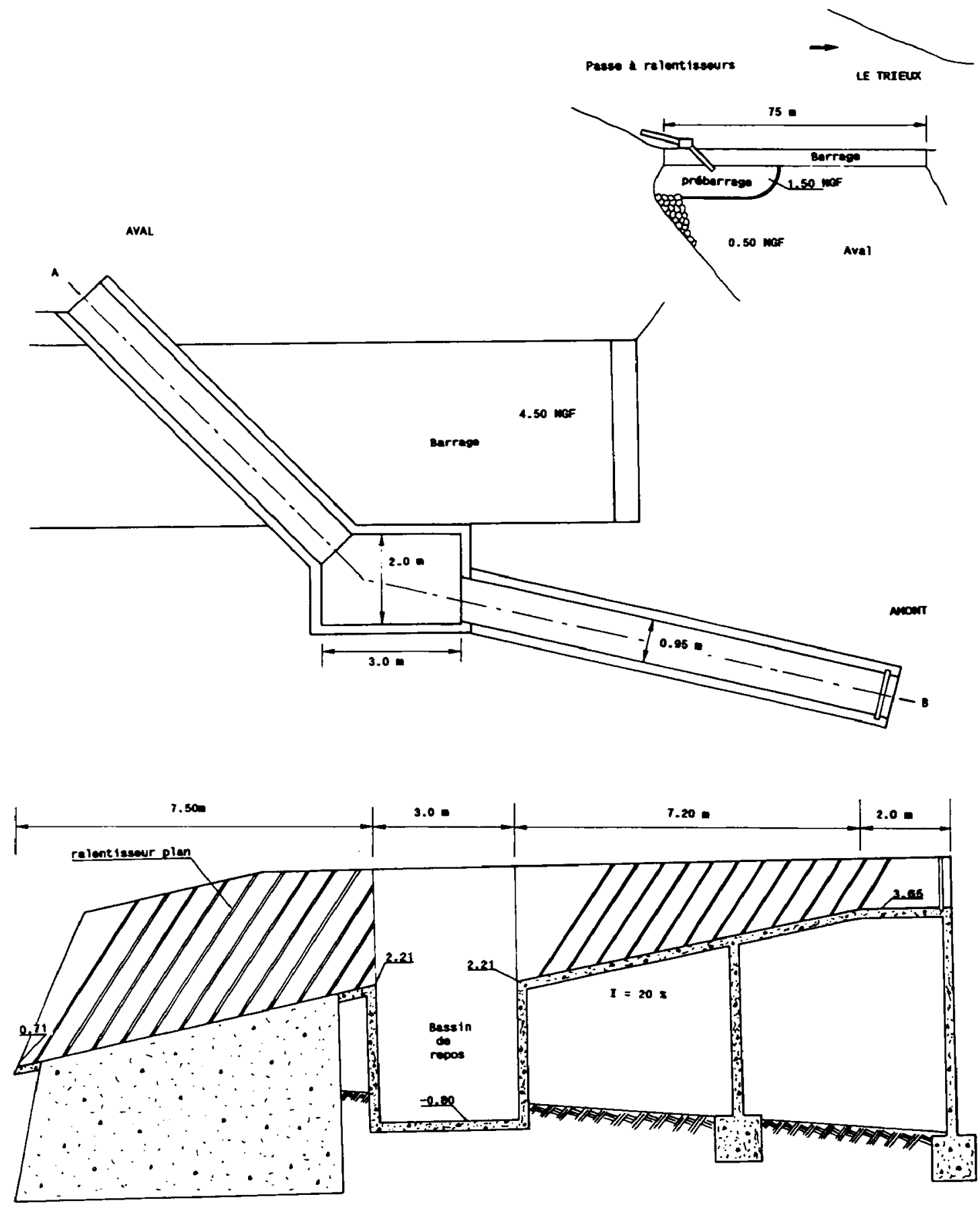
Bull. Fr. Pêche Piscic. (1992) 326-327 : 177-206 - 194 -
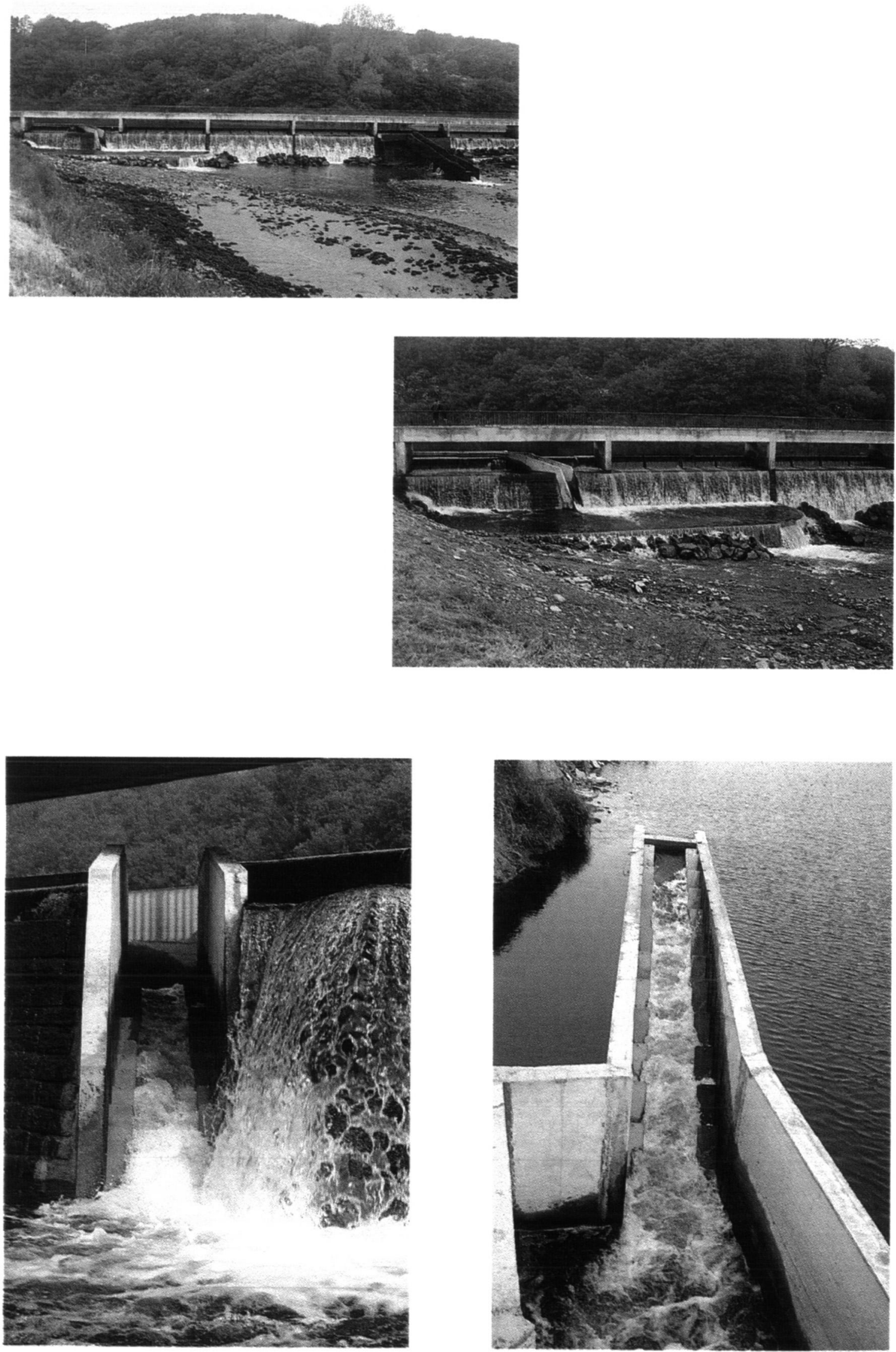


\section{PASSE A POISSONS AU BARRAGE DE CASCADEC}

(COMMUNE DE SCAER - 56)

\section{CARACTÉRISTIQUES DE L'AMÉNAGEMENT ET HYDROLOGIE}

Cours d'eau : Isole

Module : $2.1 \mathrm{~m}^{3} / \mathrm{s}$

Etiage (VCN 30 fréquence quinquennale) : $0.26 \mathrm{~m}^{3} / \mathrm{s}$

Débit résenvé : réglementairement, 1/40è du module. En fait, la quasi totalité du débit est disponible à l'exception d'une prise d'eau par pompage.

Rôle du barrage : microcentrale désaffectée. Il subsiste une prise d'eau à usage industriel.

Longueur de la dérivation : $600 \mathrm{~m}$

Longueur de crête : $20 \mathrm{~m}$

Cote NGF plan d'eau amont : 132.00

Cote NGF plan d'eau aval : 129.60

Chute maximale : $2.40 \mathrm{~m}$

Variation du niveau amont : $0.35 \mathrm{~m}$ environ

aval : $0.70 \mathrm{~m}$ environ pour $\mathrm{Q}=6.5 \mathrm{~m}^{3} / \mathrm{s}$

TYPE DE PASSE : ralentisseurs plans et prébarrage aval

Longueur de la volée : $10 \mathrm{~m}$

Largeur du canal : $0.80 \mathrm{~m}$

Pente du radier : $20 \%$

Débit de calage : $0.200 \mathrm{~m}^{3} / \mathrm{s}$

Dénivelé rattrapé par la section à ralentisseurs : $2 \mathrm{~m}$

Dénivelé restant au niveau du prébarrage : $0.40 \mathrm{~m}$

\section{COMMENTAIRES :}

La passe à ralentisseurs est positionnée dans l'angle aigu amont du barrage. L'alimentation en eau est assurée par un canal horizontal raccordé perpendiculairement à l'écoulement pour diminuer les problèmes de colmatage par les corps dérivants. Un mur partant de l'entrée de la passe (pour les poissons) évite aux migrateurs de s'engager plus en amont.

La longueur de la volée de ralentisseurs étant limitée à $10 \mathrm{~m}$ (chute $2 \mathrm{~m}$ ), le dénivelé restant $(0.40 \mathrm{~m})$ est rattrapé par un prébarrage qui offre en outre l'intérêt de constituer un matelas d'eau au pied du barrage pour la descente des smolts.

Les travaux ayant occasionné un léger abaissement du niveau aval, un deuxième prébarrage rustique a été réalisé avec des blocs d'enrochement. 


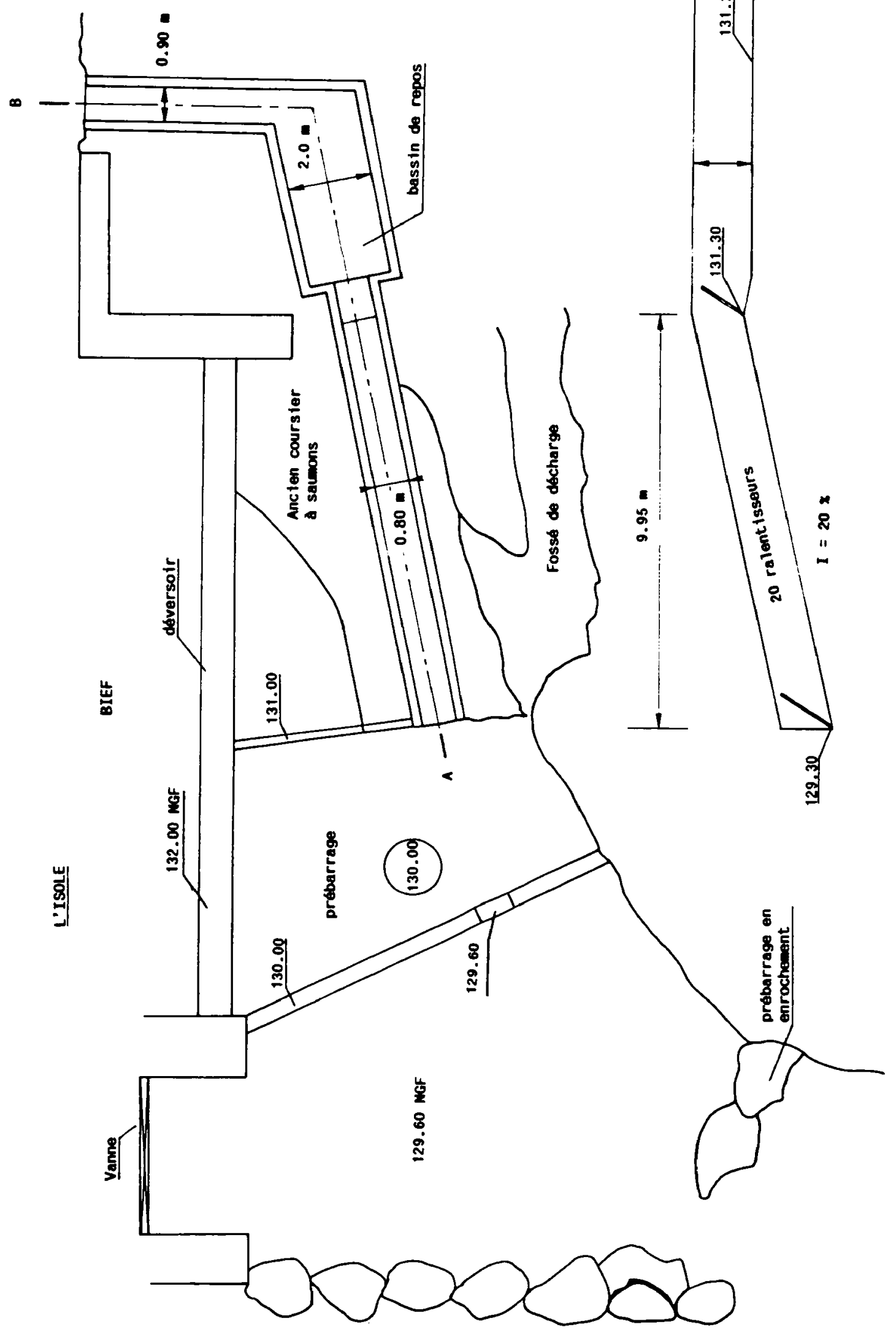


Bull. Fr. Pêche Piscic. (1992) 326-327 : 177-206 — 197 —
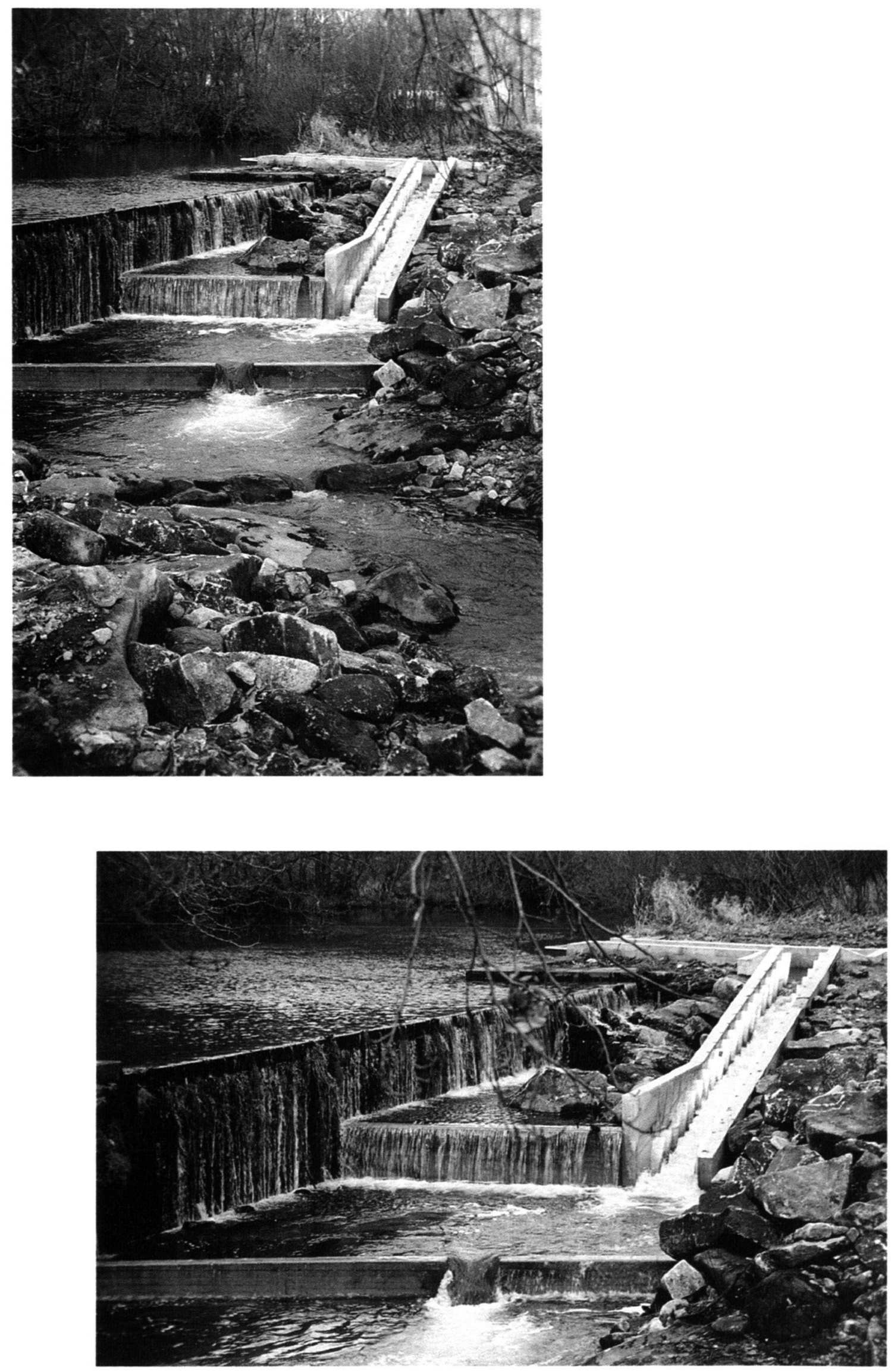


\section{PASSE A POISSONS AU BARRAGE DE MOULIN NEUF}

(COMMUNE DE SAINT CLET - 22)

\section{CARACTÉRISTIQUES DE L'AMÉNAGEMENT ET HYDROLOGIE}

Cours d'eau : Trieux

Module : $6.2 \mathrm{~m}^{3} / \mathrm{s}$

Etiage (VCN 30 quinquennal) : $0.64 \mathrm{~m}^{3} / \mathrm{s}$

Débit réservé : totalité du débit

Rôle du barrage : résidence secondaire, barrage non utilisé

Longueur de la dérivation : $50 \mathrm{~m}$

Longueur de la crête : $60 \mathrm{~m}$

Cote NGF plan d'eau amont : 17.60

Cote NGF plan d'eau aval : 16.10

Chute maximale : $1.30 \mathrm{~m}$

Variation du niveau amont : $0.35 \mathrm{~m}$ environ pour $\mathrm{Q}=20 \mathrm{~m}^{3} / \mathrm{s}$ aval : $0.70 \mathrm{~m}$ environ pour $Q=20 \mathrm{~m}^{3} / \mathrm{s}$

\section{TYPE DE PASSE : ralentisseurs de fond type chevrons épais}

Longueur de la volée : $11 \mathrm{~m}$

Largeur du canal : $1.44 \mathrm{~m}$ (pas de bandes sur les pointes de ralentisseurs)

Pente du radier : $12 \%$

Hauteur des ralentisseurs : $0.12 \mathrm{~m}$

Débit de calage : $0.500 \mathrm{~m}^{3} / \mathrm{s}$

\section{COMMENTAIRES :}

L'équipement concerne un ancien barrage de moulin de faible dénivelé, mais posant des problèmes de franchissement en étiage en raison de la faible épaisseur de la lame d'eau sur un déversoir assez long.

La passe à ralentisseurs de type chevrons épais s'intègre bien au site (pas de dépassement à l'aval du déversoir). Un bon alignement avec la direction de l'écoulement sur le déversoir a permis de supprimer les murets latéraux. Un habillage en pierres maçonnées a été réalisé sur la partie apparente.

Le coût de la réalisation est de l'ordre de $35000 \mathrm{~F}$ (1988) mais n'est pas représentatif car l'aménagement a été réalisé en colmatant une brèche existante lors de la réfection du déversoir, et seul le surcoût lié à la passe à été pris en compte (pas de frais de démolition, de batardage, etc...). 
Bull. Fr. Pêche Piscic. (1992) 326-327: 177-206 - $199-$
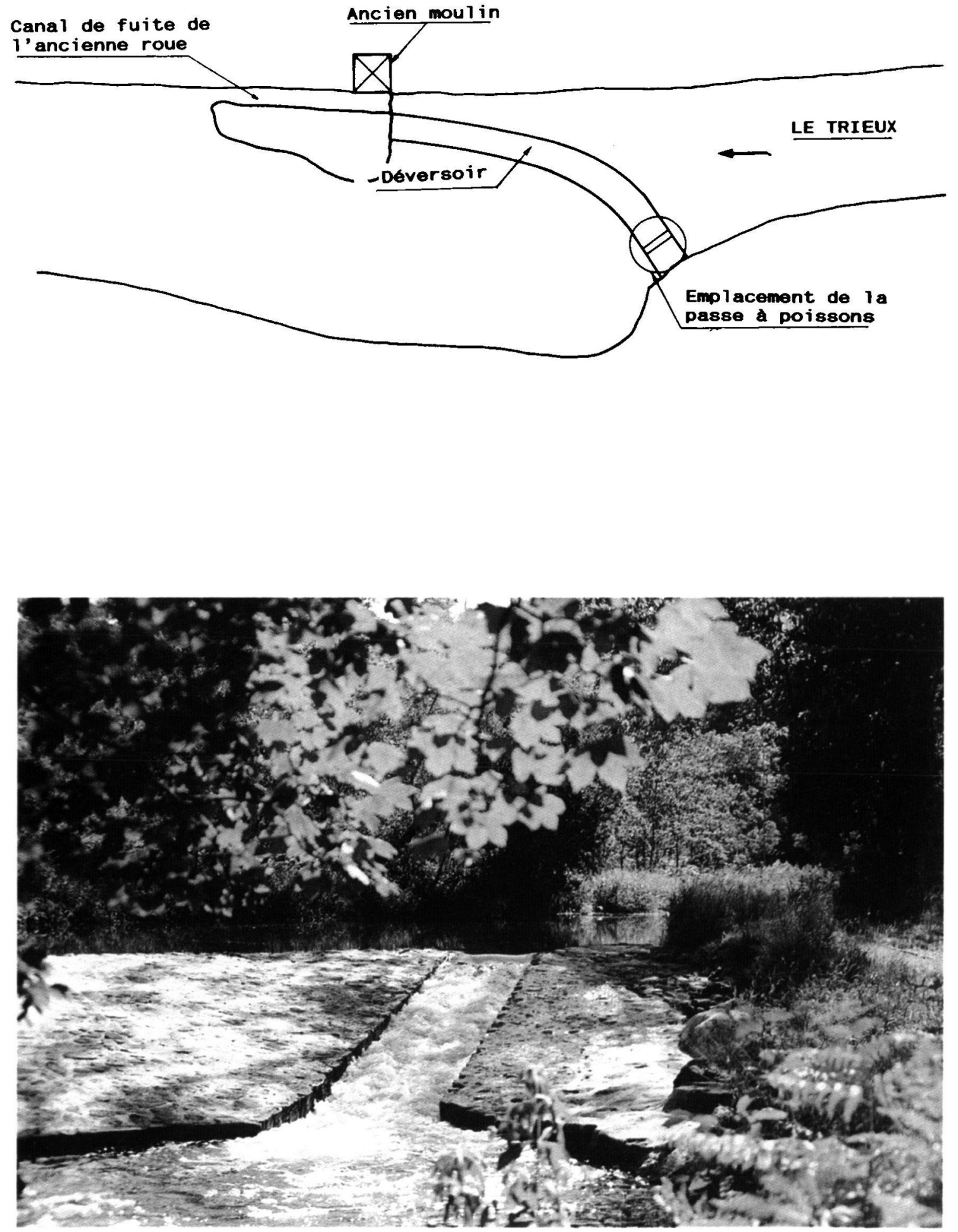


\section{ASCENSEUR A POISSONS AU BARRAGE DE KERNANSQUILLEC}

(COMMUNE DE BELLE ISLE EN TERRE - 22)

\section{CARACTÉRISTIQUES DE L'AMÉNAGEMENT ET HYDROLOGIE}

Cours d'eau : Léguer

Module : $5.2 \mathrm{~m}^{3} / \mathrm{s}$

Etiage (VCN 30 quinquennal) : $0.57 \mathrm{~m}^{3} / \mathrm{s}$

Débit réservé : $0.250 \mathrm{~m}^{3} / \mathrm{s}$

Rôle du barrage : hydroélectricité

Longueur de la dérivation : $90 \mathrm{~m}$

Longueur crête déversoir : $29.90 \mathrm{~m}$

Débit d'équipement : 3 turbines $\left(5 \mathrm{~m}^{3} / \mathrm{s}, 2 \mathrm{~m}^{3} / \mathrm{s}\right.$ et $1.8 \mathrm{~m}^{3} / \mathrm{s}$ )

Cote NGF plan d'eau amont : 80.19

Cote NGF aval étiage : 68.70

Chute maximale : $11.50 \mathrm{~m}$ environ

Variation du niveau amont : $1 \mathrm{~m}$ environ

aval : $1 \mathrm{~m}$ environ

TYPE DE PASSE : ascenseur avec accès par passe à ralentisseurs plans

\section{- Ascenseur}

Hauteur du levage : $15 \mathrm{~m}$

Dimensions de la cage $: I=1.20 \mathrm{~m} \mathrm{~L}=2.20 \mathrm{~m} \mathrm{H}=2.00 \mathrm{~m}$

Volume d'eau du bac : $0.500 \mathrm{~m}^{3}$

\section{- Passe à ralentisseurs plans}

Largeur du canal : $0.75 \mathrm{~m}$

Pente : $20 \%$

Longueur du radier : $4 \mathrm{~m}$

Dénivelé rattrapé : $0.80 \mathrm{~m}$

Débit d'alimentation : $0.250 \mathrm{~m}^{3} / \mathrm{s}$

Coût : génie civil : 130 KF (1989) ascenseur : 470 KF (1989)

\section{COMMENTAIRES :}

Les espèces concernées par l'aménagement sont les salmonidés (saumon, truite de mer, truite).

La passe à ralentisseurs plans débouche à proximité du rejet des turbines et présente une bonne attractivité pour les migrateurs. Elle donne accès à un bassin à niveau constant dans lequel est disposée la cage de l'ascenseur. On s'affranchit ainsi des variations de niveau aval, ce qui permet de diminuer la hauteur de la cage d'ascenseur.

L'ensemble du dispositif est alimenté à partir du plan d'eau amont au moyen d'un siphon $\left(0.25 \mathrm{~m}^{3} / \mathrm{s}\right)$. 


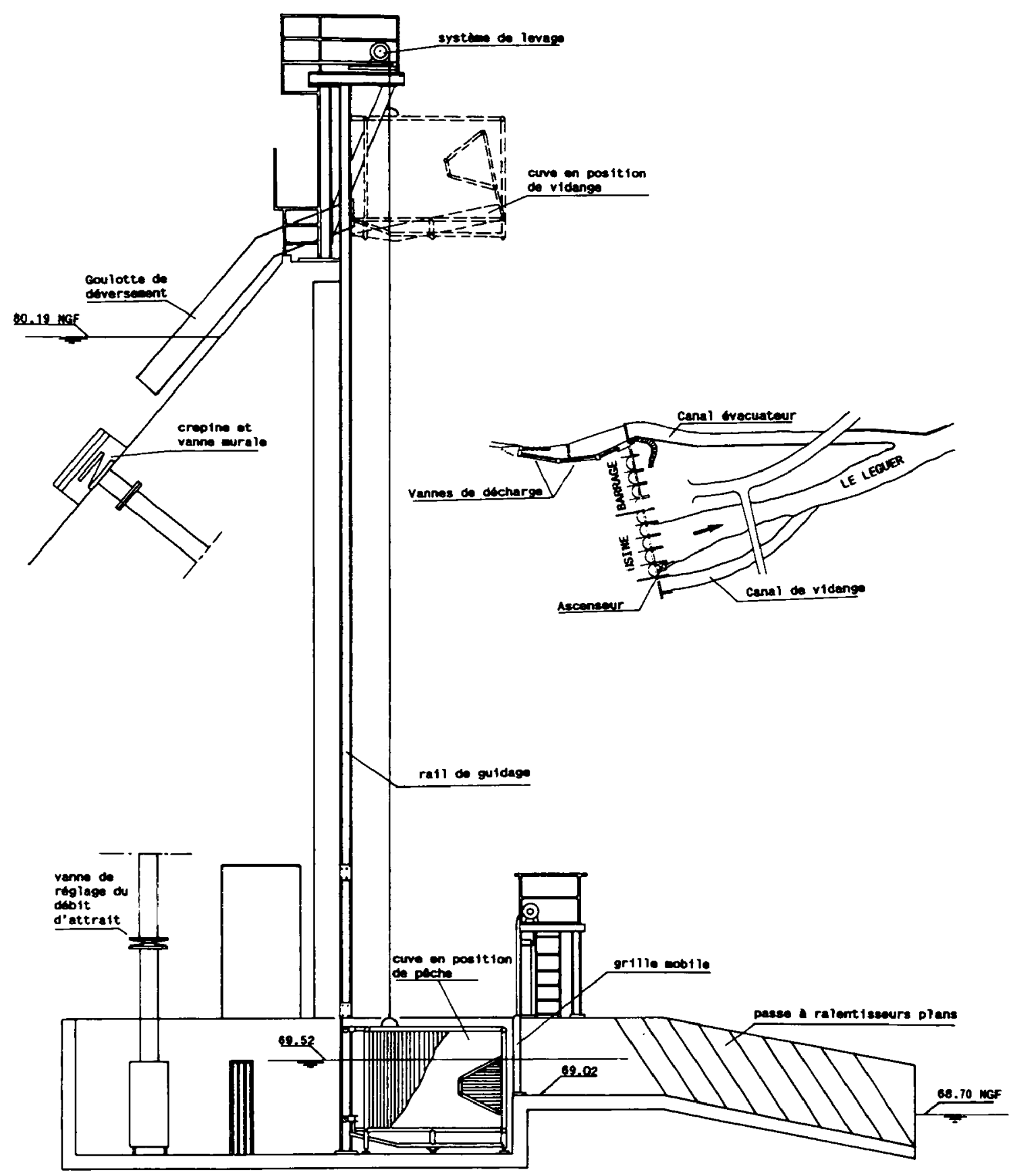



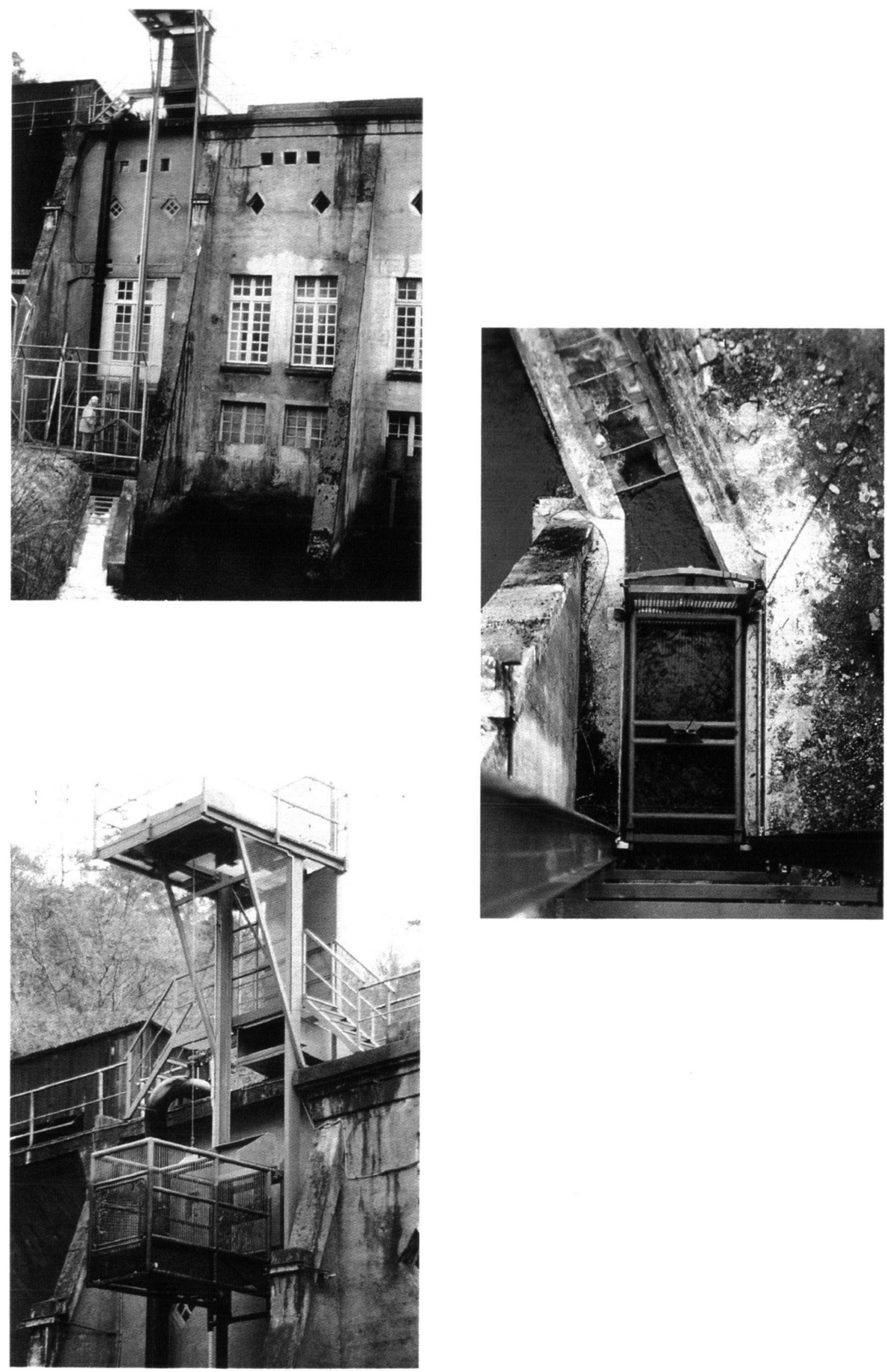


\section{PASSE A CIVELLES ET ANGUILLETTES AU BARRAGE DU MOULIN D'IFFENDIC (35)}

\section{CARACTÉRISTIQUES DE L'AMÉNAGEMENT ET HYDROLOGIE}

Cours d'eau : Meu

Module : $2.0 \mathrm{~m}^{3} / \mathrm{s}$

Débit réservé : en théorie $1 / 40^{\circ}$ du module ; en fait la totalité du débit est disponible

Rôle du barrage : ancien moulin

Longueur de la dérivation : $30 \mathrm{~m}$

Longueur crête du déversoir : $10.50 \mathrm{~m}$

Débit d'équipement : néant (barrage inutilisé pour la production hydraulique)

Cote NGF du plan d'eau amont : 38.35

Cote NGF aval étiage : 36.85

Chute maximale : $1.50 \mathrm{~m}$

Variation du niveau amont : $0.10 \mathrm{~m}$ (clapet réglable)

aval : $0.50 \mathrm{~m}$ environ pour $Q=4 \mathrm{~m}^{3} / \mathrm{s}$

\section{TYPE DE PASSE : rampe à civelles et à anguillettes}

Largeur de la rampe : $0.70 \mathrm{~m}$

Longueur de la rampe : $4 \mathrm{~m}$

Pente de la rampe : $37 \%$

Type de substrat : Anguillette (distance inter-touffes : $14 \mathrm{~mm}$ )

Coût : $8000 \mathrm{~F}$ (1989), non compris le génie civil qui a été jugé négligeable car intégré à la réfection complète du barrage à l'occasion de l'installation d'une vanne automatique.

\section{COMMENTAIRES :}

Les fluctuations du niveau amont sont modérées $(0.10 \mathrm{~m}$ de part et d'autre du niveau légal de retenue) grâce à la présence d'un clapet régulateur. La rampe a été installée avec un dévers latéral de $0.20 \mathrm{~m}$ et calée pour être alimentée sur la moitié de sa largeur au niveau normal de retenue. Elle est ainsi susceptible d'absorber les fluctuations de niveau en conservant une zone à faible tirant d'eau facilitant le passage de l'anguille.

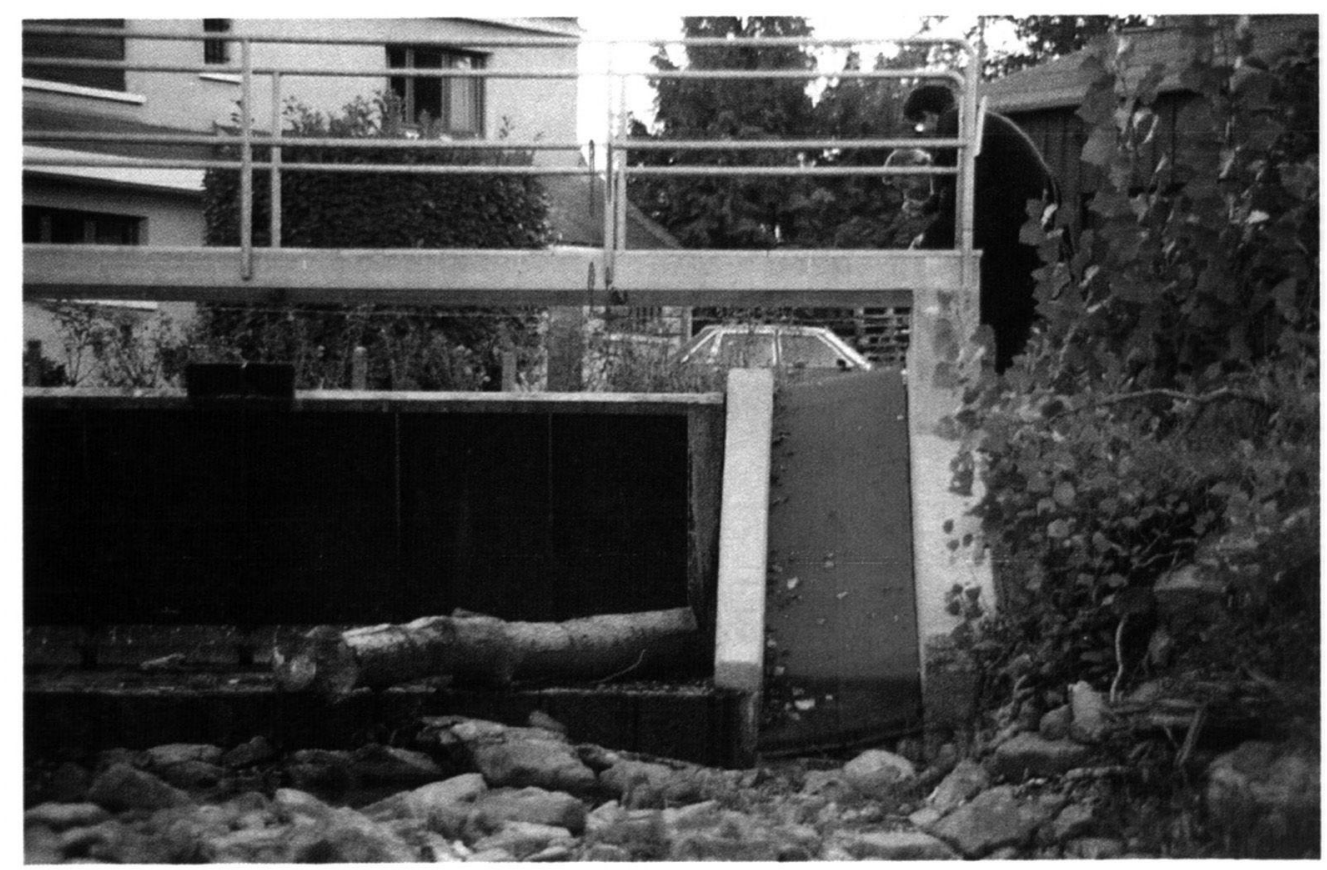



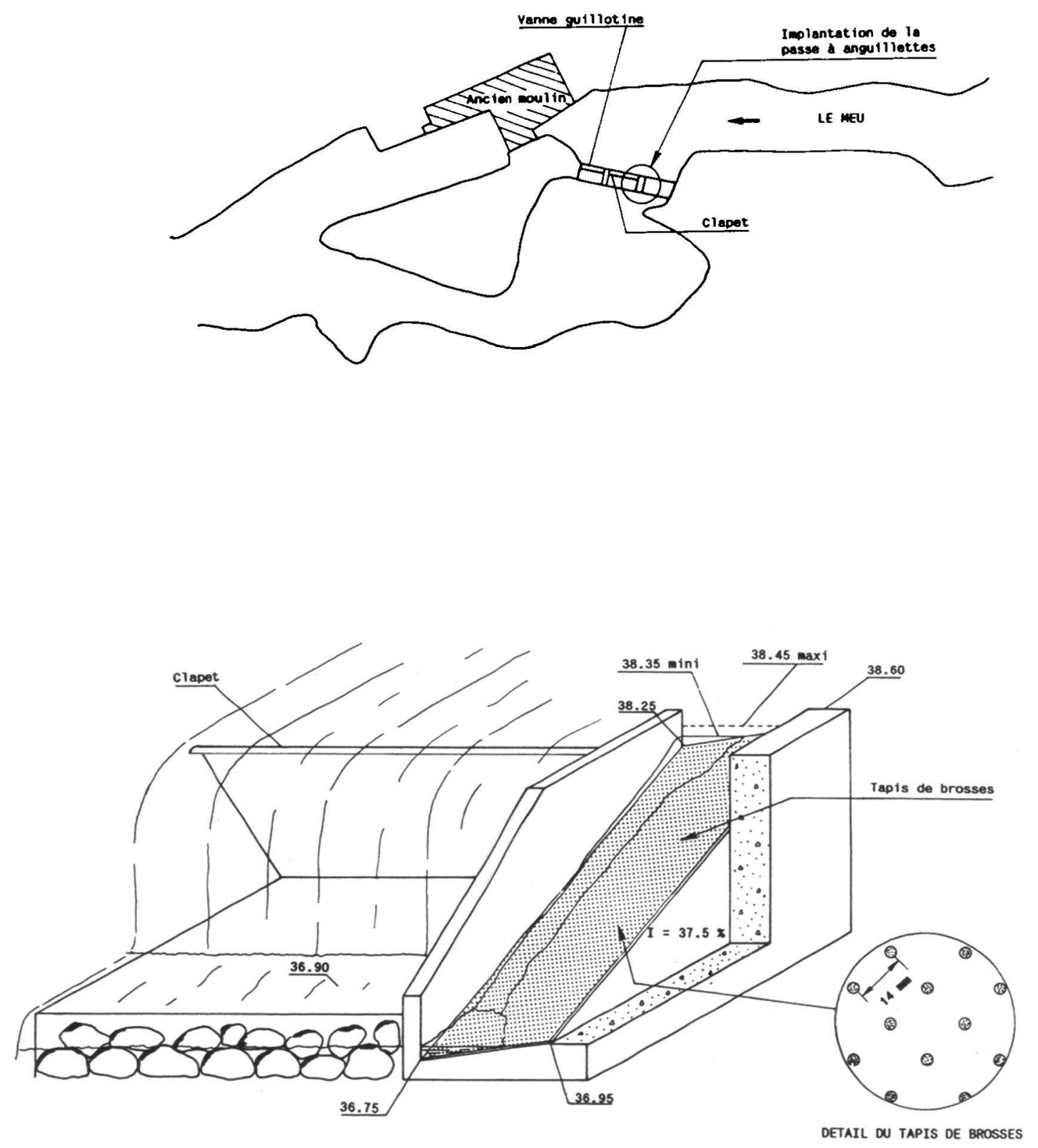


\section{PASSE A CIVELLES ET ANGUILLETTES AU BARRAGE DE LAVAU (44)}

\section{CARACTÉRISTIQUES DE L'AMÉNAGEMENT ET HYDROLOGIE}

Cours d'eau : canal de la Taillée, constituant l'un des quatre exutoires du marais du BRIVET (16.000 ha) en bordure de Loire.

Rôle du barrage : contrôle du niveau d'eau dans les marais situés à l'amont de l'ouvrage. Fonctionnement : le barrage est utilisé soit en mode "évacuation" (ouverture partielle à marée basse) soit à certaines périodes de l'année pour admettre de l'eau en amont de l'ouvrage à marée haute.

Niveau amont : variable

Variation niveau aval : soumis à la marée (mi-marée 0.60 ; plus haute mer connue 3.60)

\section{TYPE DE PASSE : Rampe à civelles et anguillettes}

\section{Largeur des rampes : $0.50 \mathrm{~m}$}

Pente des rampes : $1 / 1$

Dénivelé maximal rattrapé : $2.50 \mathrm{~m}$ avec deux bassins de repos

Type de substrat : mixte (civelles/anguillettes)

Débit de la pompe servant à l'irrigation et à l'attrait des migrateurs : $60 \mathrm{~m}^{3} / \mathrm{h}$

Coût : 75 KF (1987)

\section{COMMENTAIRES :}

Pour s'affranchir des variations de niveau du plan d'eau amont, les migrateurs progressent jusqu'à une cote supérieure au niveau amont maximal et rejoignent la retenue en contrebas par l'intermédiaire d'une canalisation "by-pass".

On observe des problèmes de dépôts de sédiments fins (vase) dans les bassins de repos. Le nombre de migrateurs empruntant le dispositif de franchissement semble corrélé positivement au débit sortant du barrage, qui permettrait d'attirer les civelles depuis le cours de la Loire, distant d'un kilomètre.

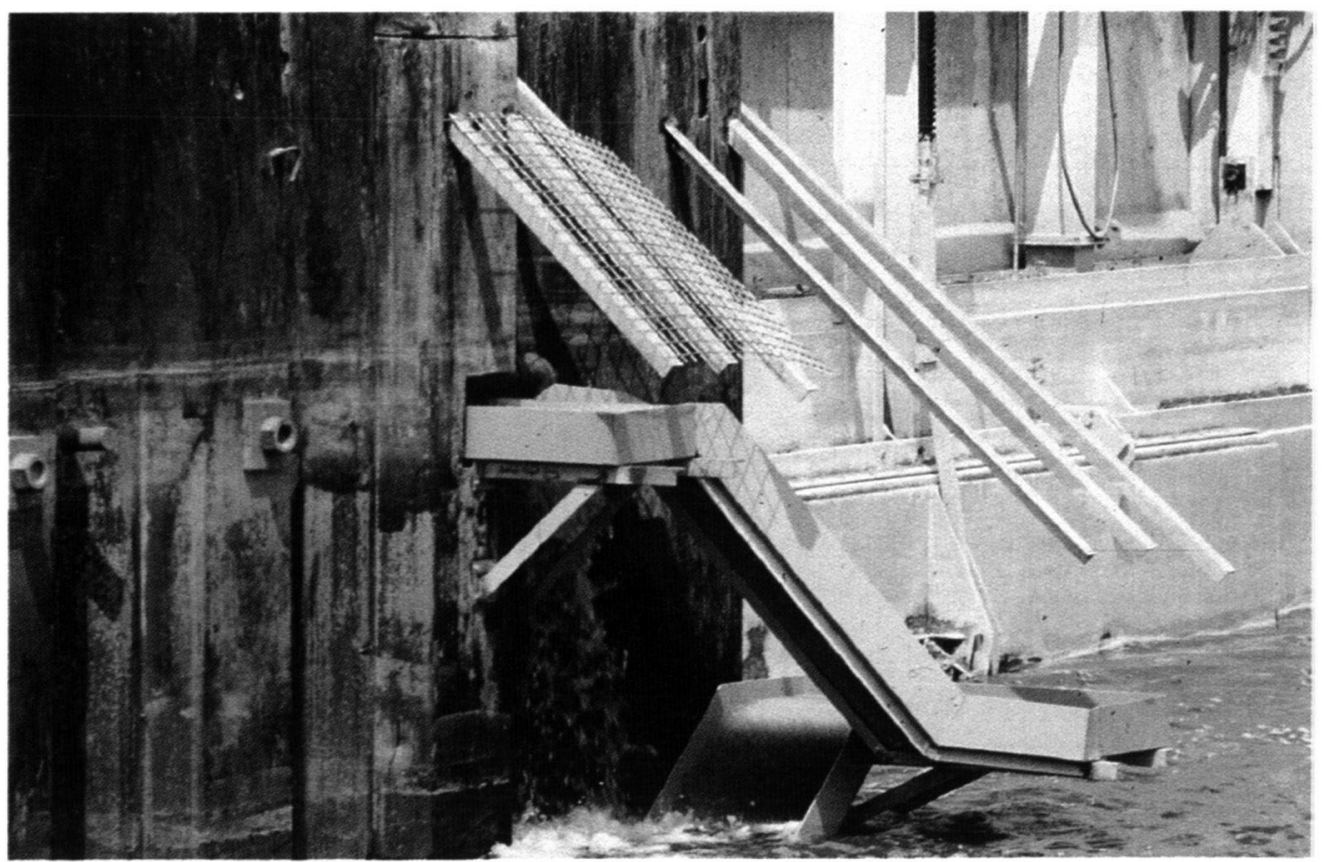



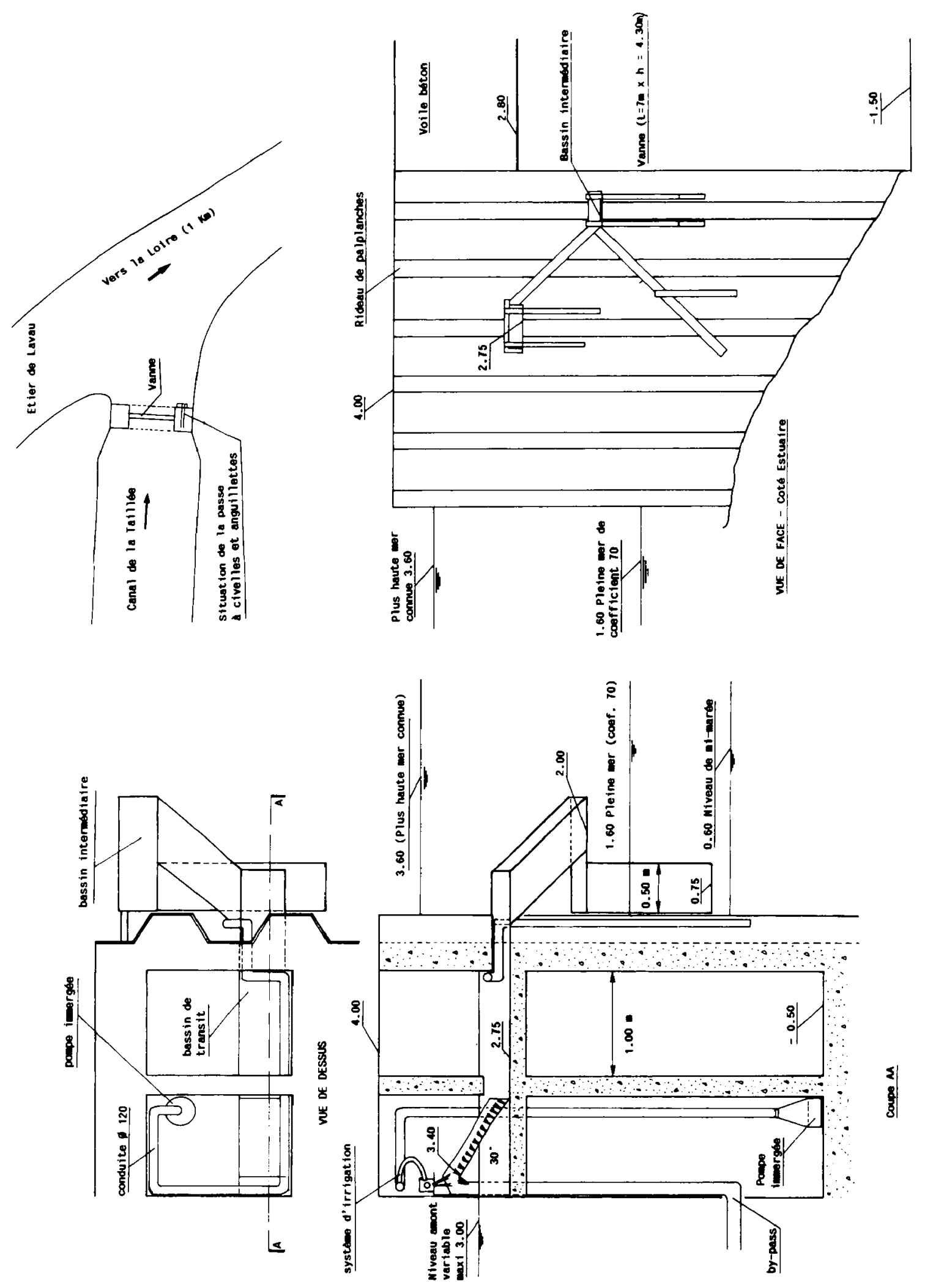